UNIVERSIDADE DE SÃO PAULO

ESCOLA DE EDUCAÇÃO FÍSICA E ESPORTE

\title{
ASSIMETRIAS INTERLATERAIS NA COORDENAÇÃO INTERARTICULAR DE MOVIMENTOS MANUAIS CIRCULARES CÍCLICOS
}

\author{
Carla Ferro Pereira
}

SÃO PAULO

2011 


\title{
ASSIMETRIAS INTERLATERAIS NA COORDENAÇÃO INTERARTICULAR DE MOVIMENTOS MANUAIS CIRCULARES CÍCLICOS
}

\author{
CARLA FERRO PEREIRA
}

Dissertação apresentada à Escola de Educação Física e Esporte da Universidade de São Paulo, como requisito parcial para obtenção do grau de Mestre em Educação Física. 


\section{AGRADECIMENTOS}

Primeiramente, agradeço aos meus pais, Laura Terra Ferro Pereira e Moacir Pereira, por todos os momentos que estiveram me dando suporte emocional para enfrentar tantos obstáculos. Devo a alegria que sinto neste momento tão importante a eles. Agradeço também aos meus irmãos Bruno e Camila pelo apoio incentivo durante todo esse tempo.

Ao meu companheiro Odair Monfredini Junior, que além de ser compreensivo, me ajudou muitas vezes em todas as fases do mestrado. Sempre muito paciente, emprestando o seu ombro nos momentos difíceis, me tranquilizando de que tudo daria certo e me incentivando sempre a ir em busca dos meus sonhos. Obrigada por entender minhas ausências e os meus vários momentos de ansiedade extrema.

Um agradecimento muito especial ao professor Dr. Luis Teixeira, por me ensinar com tanta sutileza e dedicação o caminho percorrido até aqui e por me apoiar e me guiar, tendo em vista uma perspectiva ainda maior do que apenas concluir esta etapa.

Agradeço profundamente aos meus colegas de laboratório Sistemas Motores Humanos: Victor (pelos ensinamentos, pelos incentivos, por acreditar na minha capacidade, pelo grande auxílio no ingresso ao mestrado), Andréa (pelos ensinamentos, pelos incentivos, pelo ombro amigo, pelos grandes conselhos de vida), Ana Paula (pelos ensinamentos, pelo auxílio nas coletas de dados), Natália (pela grande ajuda no término da aprendizagem do manuseio do sistema opto-eletrônico Vicon Nexus, pelo auxílio nas coletas, pelas nossas conversas sobre tudo), Marina (pelo incentivo, por auxiliar intensivamente na 
coleta do estudo piloto) e Daniel (por auxiliar com alguns cálculos). Em especial, agradeço ao colega Raymundo por me ensinar e desenvolver as rotinas do Matlab. Muito obrigada pela atenção despendida a mim nesse período de análise dos dados, por me explicar vários cálculos matemáticos, obrigada por tudo. Enfim, aprendi muito com vocês! Vocês estiveram e estão comigo no mesmo barco, por isso, quero repartir com vocês a alegria e satisfação por trabalhar ao lado de pessoas que também valorizam a ciência.

Meus agradecimentos ao professor e Dr. Luis Mochizuki por me auxiliar em algumas dúvidas relacionadas à análise de dados. Sempre muito atencioso e profissional.

Aos funcionários da secretaria de pós-graduação, Ilza e Márcio, que sempre se mostraram muito atenciosos.

Nenhuma conquista seria possível sem a presença constante de Deus na minha vida.

Em especial, agradeço ao apoio financeiro do $\mathrm{CNPq}$ sem o qual este trabalho não teria sido possível. 


\section{SUMÁRIO}

\section{PÁGINA}

LISTA DE TABELAS................................................................................... vii

LISTA DE FIGURAS............................................................................. viii

LISTA DE APÊNDICE......................................................................

RESUMO.................................................................................................. xii

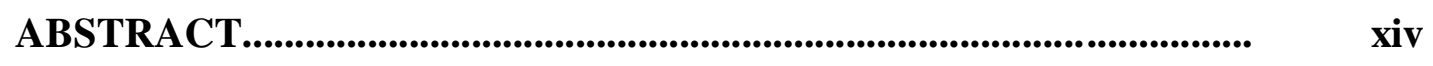

1 INTRODUÇÃO

$2 \quad$ REVISÃO DA LITERATURA.............................................................. 3

2.1 Assimetrias intermanuais de desempenho motor......................................... 3

2.2 Assimetrias interlaterais de desempenho motor na realização de

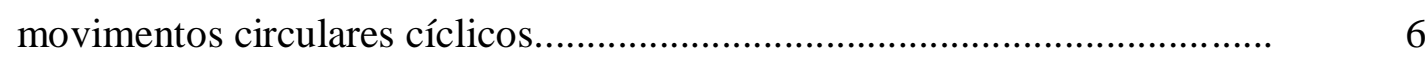

2.2.1 Coordenação interarticular de movimentos cíclicos realizados com o braço dominante em função do aumento da velocidade de movimento................. 8

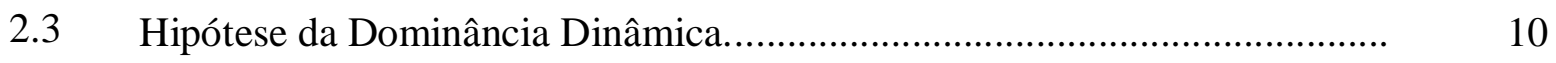

$3 \quad$ OBJETIVO.................................................................................... 13

$4 \quad$ JUSTIFICATIVA.......................................................................................

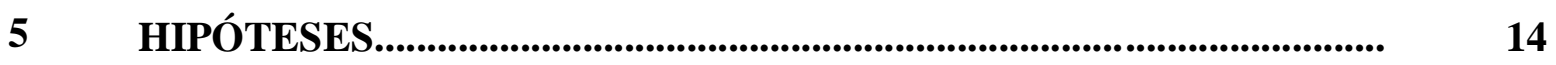

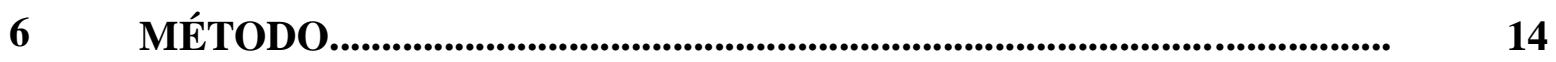



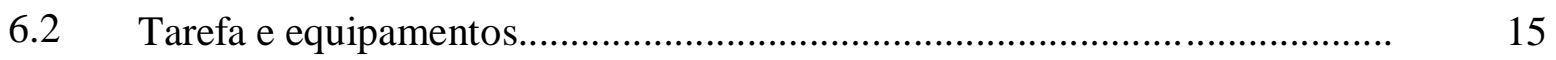

6.3 Delineamento e procedimentos experimentais......................................... 18

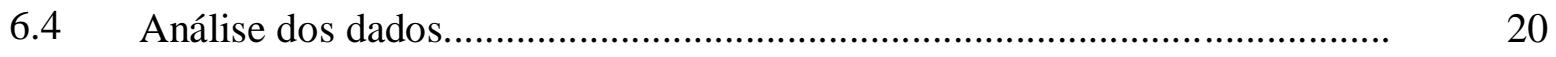

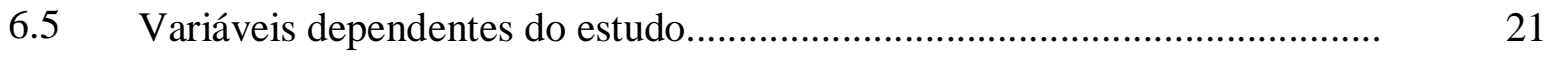

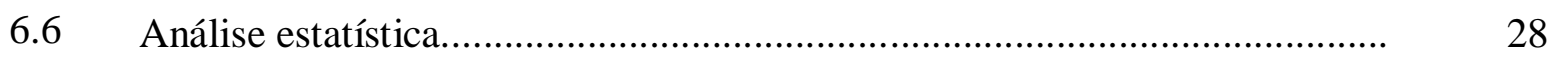

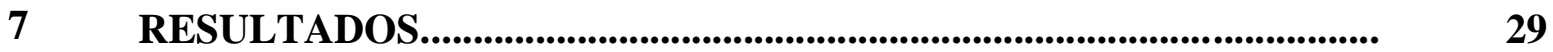


8 DISCUSSÃO

8.1 Assimetrias interlaterais de desempenho motor........................................... 46

8.2 Efeito da frequência de movimentos sobre as assimetrias interlaterais na coordenação interarticular..

8.3 Relação entre variabilidade e velocidade de movimento.............................. 55

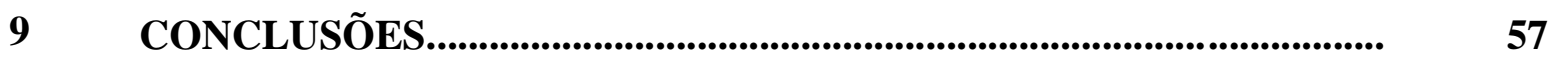

10 SUGESTÕES PARA ESTUDOS FUTUROS........................................ 58

REFERÊNCIAS.......................................................................... 59

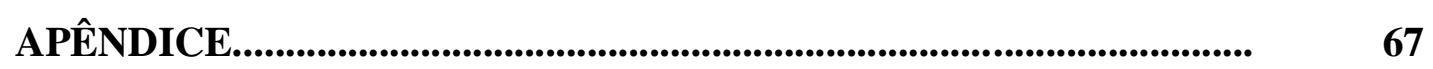




\section{LISTA DE TABELAS}

Página

TABELA 1 - Síntese do delineamento e procedimentos experimentais

TABELA 2 - Média e erro padrão da frequência de movimentos $(\mathrm{Hz})$ nas cinco frequências avaliadas. 


\section{LISTA DE FIGURAS}

Página

FIGURA 1 - Representação esquemática da tarefa experimental, indicando o posicionamento dos instrumentos e do participante na realização da tarefa. Figura (a), representação da tarefa com o braço não-dominante no sentido horário, e figura (b), representação da tarefa com o braço dominante no sentido antihorário.

FIGURA 2 - Representação da circularidade da trajetória produzida durante o deslocamento linear do marcador do punho nos eixos $x$ e $y$ em uma tentativa. Setas no interior do círculo indicam a amplitude de movimento em cada eixo.

FIGURA 3 - Representação do deslocamento angular do ombro e do cotovelo durante movimentos circulares do braço dominante. A letra $a$ indica a amplitude angular na articulação do cotovelo. A seta vertical indica o sentido de flexão do cotovelo e adução do ombro.

FIGURA 4 - Representação do deslocamento angular do ombro e do cotovelo durante movimentos circulares do braço, com indicação dos intervalos usados para calcular a fase relativa

FIGURA 5 - Médias e erros-padrão (traços verticais) do erro circular no eixo $x$ (a) e eixo $y$ (b), dos braços dominante e não-dominante em função da frequência relativa de movimento

FIGURA 6 - Médias e erros-padrão (traços verticais) do erro temporal (ms) do braço dominante e do braço nãodominante em função da frequência relativa de movimento.

FIGURA 7 - Médias e erros-padrão (traços verticais) da variabilidade do erro temporal do braço dominante e do braço não-dominante em função da frequência relativa de movimento. 
FIGURA 8 - Trajetória dos movimentos circulares produzida com o braço não-dominante e braço dominante por um participante em diferentes frequências relativas de movimento.

FIGURA 9 - Médias e erros-padrão (traços verticais) do índice de circularidade do movimento dos braços dominante e não-dominante em função da frequência relativa de movimento

FIGURA 10 - Médias e erros-padrão (traços verticais) da variabilidade da circularidade do movimento dos braços dominante e não-dominante em função da frequência relativa de movimento

FIGURA 11 - Médias e erros-padrão (traços verticais) da amplitude angular do ombro (a) e cotovelo (b), dos braços dominante e não-dominante em função da frequência relativa de movimento

FIGURA 12 - Médias e erros-padrão (traços verticais) da variabilidade da amplitude angular do ombro (a) e cotovelo (b), dos braços dominante e não-dominante em função da frequência relativa de movimento...........

FIGURA 13 - Média (linha contínua) e variabilidade (linhas tracejadas) da relação espacial entre as medidas angulares do ombro e cotovelo em movimentos realizados com o braço dominante e braço nãodominante em diferentes frequências de movimento....

FIGURA 14 - Médias e erros-padrão (traços verticais) do coeficiente de amplitude ângulo-ângulo dos braços dominante e não-dominante em função da frequência relativa de movimento

Médias e erros-padrão (traços verticais) da variabilidade do coeficiente ângulo-ângulo do braço dominante e do braço não-dominante em função da frequência relativa de movimento.

FIGURA 16 - Representação da relação temporal do deslocamento angular do ombro e do cotovelo durante movimentos circulares cíclicos do braço dominante (a) e nãodominante (b) realizado em $70 \%$ da frequência 
máxima.

FIGURA 17 - Médias e erros-padrão (traços verticais) da fase relativa do braço dominante e não-dominante em função da frequência relativa de movimento.

FIGURA 18 - Médias e erros-padrão (traços verticais) da variabilidade da fase relativa (FR) do braço dominante e do braço não-dominante em função da frequência relativa de movimento................................................. 


\section{LISTA DE APÊNDICE}

Página

APÊNDICE 1 - Inventário de Dominância Lateral de Edimburgo

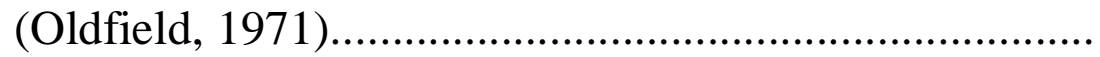


RESUMO

\section{ASSIMETRIAS INTERLATERAIS NA COORDENAÇÃO INTERARTICULAR DE MOVIMENTOS MANUAIS CIRCULARES CÍCLICOS}

\section{Autor: CARLA FERRO PEREIRA \\ Orientador: PROF. DR. LUIS AUGUSTO TEIXEIRA}

A dominância lateral para controle motor tem sido proposta ser devida a uma capacidade superior em lidar com a dinâmica do movimento com o hemisfério/lado corporal dominante. A partir desta hipótese, é esperado que o braço dominante apresente tanto trajetórias mais precisas quanto modos de coordenação mais estáveis. Além disso, tal assimetria motora deveria ser mais evidente em movimentos mais rápidos. No presente estudo foi avaliada a assimetria interlateral de desempenho na coordenação interarticular/ intramembro em movimentos realizados em diferentes frequências. Foi analisada a coordenação interarticular entre o ombro e o cotovelo do mesmo braço em uma tarefa de realizar movimentos circulares com as mãos, comparando o desempenho entre os braços dominante e não-dominante. $\mathrm{O}$ estudo foi realizado com 16 adultos jovens, que realizaram a tarefa em cinco frequências de movimento, variando de $40 \%$ a $100 \%$ da frequência individual máxima. Movimentos angulares das articulações foram analisados através de marcadores 
refletivos fixados no ombro, cotovelo e punho de ambos os braços. Os marcadores foram rastreados automaticamente por meio de um sistema optoeletrônico, com frequência de aquisição de $240 \mathrm{~Hz}$, e análise em 3D. Os resultados demonstraram que o desempenho com o braço não-dominante apresentou as seguintes diferenças em comparação com o braço dominante: trajetória da mão e amplitudes angulares mais variáveis, maior participação do cotovelo, coordenação em modo antifase (braço dominante: relação de fase de aproximadamente $120^{\circ}$ ) e maior variabilidade de modo de coordenação. De forma geral, as assimetrias interlaterais foram acentuadas em frequências de movimento mais altas. Estes resultados indicam que a vantagem de desempenho com o braço dominante é devida a um modo de coordenação mais consistente e efetivo em realizar a trajetória desejada.

Palavras-chave: assimetria interlateral, dominância lateral, movimentos cíclicos circulares 


\begin{abstract}
INTERLATERAL ASYMMETRIES IN INTERJOINT COORDINATION ON CYCLIC CIRCULAR MANUAL MOVEMENTS
\end{abstract}

\author{
Author: CARLA FERRO PEREIRA \\ Adviser: PROF. DR. LUIS AUGUSTO TEIXEIRA
}

Lateral dominance for motor control has been proposed to be due to a superior capacity to deal with motion dynamics with the dominant cerebral hemisphere/body side. From this conjecture, it is expected the dominant arm to present both an increased capacity to perform more accurate trajectories and a more stable interjoint coordination. Moreover, such motor asymmetry should be more evident in fast movements. We assessed interjoint coordination between the shoulder and the elbow on a circle drawing task, comparing performance between the dominant and the non-dominant arm. The study was conducted with 16 young adults, who performed the task on five movement frequencies, ranging from $40 \%$ to $100 \%$ of the individual maximum. Angular motion of the joints was recorded through reflective markers attached at the shoulder, elbow and wrist of both arms. Markers were tracked automatically by using an optoelectronic system, with data sampling frequency set at $240 \mathrm{~Hz}$, and 3D analysis. The results showed that performance with the non-dominant arm had the following 
differences in comparison with the dominant arm: more variable hand trajectory and joint amplitudes, interjoint coordination in antifase (dominant arm: phase relation of approximately $120^{\circ}$ ) and increased variability in the coordination mode. Overall, interlateral asymmetries were amplified in higher movement frequencies. These results indicate that the advantage of the dominant arm resides in a more stable and effective mode of coordination in performing the desired trajectory.

Keywords: interlateral asymmetry, lateral dominance, cyclical circular movements. 


\section{INTRODUÇÃO}

Assimetria de desempenho favorável ao braço dominante tem sido encontrada em uma série de tarefas motoras, tais como toques repetitivos com máxima velocidade (PETERS, 1976, 1981), toque discreto em um alvo (FLOWERS, 1975; ROY \& ELLIOT, 1986, 1989; SAINBURG, 2002; BAGESTEIRO \& SAINBURG, 2005; SCHAEFER, HAALAND \& SAINBURG, 2007), tarefas de força máxima (PROVINS, MILNER \& KERR, 1982) e em tarefas de desenhar círculos (KELSO, 1984; CARSON, THOMAS, SUMMERS, WALTERS \& SEMJEN, 1997; CATTAERT, SEMJEN \& SUMMERS, 1999; BYBLOW, SUMMERS, SEMJEN, WUYTS \& CARSON, 1999; VERSCHUEREN, SWINNEN, CORDO \& DOUNSKAIA, 1999; FRANZ, ROWSE \& BALLANTINE, 2002; SPENCER, IVRY, CATTAERT \& SEMJEN, 2005; TSENG \& SCHOLZ, 2005; DOUNSKAIA, NOGUEIRA, SWINNEN \& DRUMMOND, 2010). Em relação à tarefa de desenhar círculos, tem sido observado que movimentos realizados com o braço não-dominante são mais variáveis em tamanho (FRANZ et al., 2002; TSENG \& SCHOLZ, 2005, 2006), e na configuração espacial (CARSON et al., 1997; CATTAERT et al., 1999; TSENG \& SCHOLZ, 2006; DOUNSKAIA et al., 2010). Tal variabilidade no desempenho com o braço não-dominante fica evidente principalmente em altas velocidades de movimento.

Uma proposição que pode ser usada como explicação da assimetria de desempenho entre os braços na tarefa de desenhar círculos é a hipótese da dominância dinâmica de SAINBURG (2002), a qual propõe que o sistema hemisférico cerebral esquerdo/braço direito é especializado no controle da trajetória do membro, enquanto que o sistema homólogo contralateral é especializado no controle da posição final do membro. Esta hipótese emergiu de 
estudos demonstrando a superioridade do braço dominante (direito) no controle da dinâmica intersegmentar, conforme solicitado para especificação da trajetória da mão durante movimentos de alcançar um alvo (SAINBURG \& KALAKANIS, 2000; SAINBURG, 2002; BAGESTEIRO \& SAINBURG, 2005; SCHAEFER et al., 2007). Especificações da trajetória da mão são dependentes da coordenação interarticular e do controle da dinâmica intersegmentar (SAINBURG, GHILARDI, POIZNER \& GHEZ, 1995). Em geral, os resultados de Sainburg e colaboradores demonstraram que o braço dominante é mais eficiente em lidar com as forças geradas em cada articulação envolvida no movimento, resultando em um movimento mais retilíneo, em comparação ao braço não-dominante. De acordo com essa proposição, o controle do movimento do braço dominante se distinguiria pela programação da ação (organização via feedforward), enquanto que o movimento do braço não-dominante se distinguiria principalmente pelo uso de mecanismos de feedback no posicionamento final da mão sobre o alvo espacial (ver também BAGESTEIRO \& SAINBURG, 2002, 2003; SAINBURG, 2005).

Uma vez que em tarefas de realizar movimentos circulares cíclicos o componente principal é a trajetória da mão de execução, a hipótese de dominância dinâmica permite prever que o desempenho com o braço dominante é superior ao desempenho com o braço não-dominante. Em função da hipotética superioridade no controle da dinâmica intersegmentar, é esperado que o braço dominante apresente não apenas maior capacidade de realizar movimentos circulares, mas também apresente um modo de coordenação interarticular mais estável. No presente estudo foi avaliada a extensão em que a assimetria interlateral de desempenho na coordenação interarticular é modificada em movimentos realizados em altas frequências. 


\section{REVISÃO DE LITERATURA}

2.1 Assimetrias intermanuais de desempenho motor

Resultados de pesquisa têm mostrado que em determinadas tarefas motoras é observada assimetria interlateral de desempenho favorável ao braço dominante. Tal assimetria tem sido encontrada em tarefas de toques repetitivos com máxima velocidade (PETERS, 1976, 1981), toque discreto em um alvo (FLOWERS, 1975; ROY \& ELLIOT, 1986, 1989; SAINBURG, 2002; BAGESTEIRO \& SAINBURG, 2005; SCHAEFER et al., 2007), tarefas de força máxima (PROVINS et al., 1982) e em tarefas cíclicas de desenhar círculos (KELSO, 1984; CARSON et al., 1997; CATTAERT et al., 1999; BYBLOW et al., 1999; VERSCHUEREN et al., 1999; FRANZ et al., 2002; SPENCER et al., 2005; TSENG \& SCHOLZ, 2005; DOUNSKAIA et al., 2010). Esse dado é um indicativo de que existem assimetrias na constituição dos dois hemisférios cerebrais, tornando um dos lados do corpo mais apto a desempenhar determinadas funções sensoriomotoras do que o lado contrário. Uma dessas funções corresponde a contrações rápidas e alternadas de músculos flexores e extensores das mãos, gerando movimentos oscilatórios de alta frequência de toques sequenciais em uma superfície (PETERS, 1980, 1981). Outra função consiste na realização de movimentos envolvendo velocidade e precisão em movimentos orientados a um alvo espacial (FLOWERS, 1975; ROY \& ELLIOT, 1986, 1989; SAINBURG, 2002; BAGESTEIRO \& SAINBURG, 2005; SCHAEFER et al., 2007).

Estudos prévios foram realizados com o objetivo de analisar os processos de controle motor que fundamentam a vantagem de desempenho do braço dominante sobre o braço não-dominante em ações de toques sequenciais ou em 
toque discreto em um alvo (e.g., ANNET et al., 1979; PETERS, 1980, 1981; ROY \& ELLIOT, 1986, 1989; ROY, KALBFLEISH et al., 1994). Com relação à função de controle de toques sequenciais em uma superfície, tem sido demonstrado que o desempenho com o braço dominante é consistentemente superior, não apenas em termos de frequência, mas também de variabilidade temporal dos movimentos (PETERS, 1980, 1981). PETERS (1980) demonstrou que as diferenças de desempenho entre o braço dominante e não-dominante nessa tarefa foram altamente consistentes. Este resultado corresponde à evidência de que estas assimetrias estão relacionadas à modulação superior de força no controle do braço dominante. Tal controle seria responsável por ciclos rápidos de contração/relaxamento de grupos musculares antagônicos do punho para produzir movimentos de flexão/extensão com altas frequências. A assimetria de desempenho em tarefas de toques discretos em um alvo foi avaliada com relação a variáveis de velocidade de movimento e precisão de contato. De uma forma geral, os resultados têm indicado que os movimentos feitos com o braço dominante são mais rápidos e mais precisos do que aqueles realizados com o braço não-dominante (FLOWERS, 1975; ROY \& ELLIOT, 1986, 1989). Uma explicação para a assimetria motora nessa tarefa com vantagem de desempenho favorável ao braço dominante foi proposta por ANNET et al. (1979) com base no modelo de variabilidade do impulso de SCHMIDT et al. (1978).

O modelo de variabilidade do impulso propõe que o aumento na velocidade e aceleração demanda maior geração de força durante a realização do movimento. Essa maior geração de força tem sido diretamente associada à variabilidade de movimento e, consequentemente, à menor precisão de movimento. Esse modelo é baseado na idéia de que a maior produção de força causaria maior ruído neural no sistema, proporcionando maior variabilidade de 
movimento e menor precisão. Nesse contexto, a geração de forças musculares diferentes daquelas desejadas pelo indivíduo é interpretada como sendo resultante de um ruído neural na geração dos sinais eferentes para o sistema muscular. ANNET et al. (1979) propôs que o sistema neuromotor dominante consegue lidar de forma mais precisa com as forças geradas no movimento, resultando em uma menor variabilidade do movimento e menor tempo de movimento. O maior tempo de movimento para o braço não-dominante seria originário da maior variabilidade de movimentos efetuados com esse braço. Como movimentos erráticos necessitam de maior número de correções, a maior variabilidade de movimento exigiria mais tempo para que os ajustes fossem efetuados. Tais resultados indicam menor capacidade do sistema neuromotor não-dominante em lidar com as forças geradas no início do movimento. Outro estudo que sustenta essa explicação foi realizado por ROY e ELLIOT (1986), no qual era solicitado que os participantes realizassem uma série de movimentos de contato rápido com um alvo espacial, variando o tempo de movimento manual entre 100 e 400 ms. Metade das tentativas era efetuada com visão completa e na outra metade a luz era apagada imediatamente após o início do movimento. A racionalidade do estudo foi de que, se o desempenho com o braço dominante se diferencia pelo processamento de feedback visual, a eliminação dessa fonte de aferência deveria prejudicar mais o desempenho com o braço dominante do que com o braço não-dominante. Os resultados demonstraram que o braço dominante apresentou o mesmo desempenho tanto na condição de visão completa quanto na condição sem visão na situação de tempo de movimento mais longo. Por outro lado, a vantagem para o braço dominante foi evidente no tempo de movimento mais curto. Estes resultados corroboram a proposição de ANNET et al. (1979) de que o sistema neuromotor dominante consegue lidar de forma mais precisa com 
as forças geradas no movimento, favorecendo uma aproximação mais rápida e mais precisa ao alvo.

2.2 Assimetrias interlaterais de desempenho motor na realização de movimentos circulares cíclicos

Como citado na seção anterior, quando a análise do comportamento motor é centrada na qualidade de controle de movimentos circulares cíclicos, também têm sido encontradas assimetrias manuais de desempenho. Em um estudo realizado por CARSON et al. (1997) foram analisados movimentos circulares no sentido horário e anti-horário, tanto com o braço dominante quanto com o braço não-dominante. Participaram do estudo sujeitos destros, no qual foram solicitados a completar o ciclo de movimento a cada toque do metrônomo, sendo que a frequência do metrônomo aumentava de forma progressiva. Os movimentos circulares foram realizados contornando um círculo com a ponta do dedo indicador, no qual um marcador reflexivo foi fixado para análise do movimento. Os resultados demonstraram que a frequência de movimento do braço dominante tendeu a ser adiantada em relação à frequência do metrônomo em todas as condições. O braço não-dominante apresentou um atraso na sincronização entre a frequência de movimento e a frequência do metrônomo. Com relação à circularidade do movimento, a trajetória do braço dominante foi mais circular do que a trajetória do braço não-dominante nas diferentes frequências de movimento. Por fim, o braço não-dominante mostrou maior variabilidade espacial do movimento em comparação ao braço dominante com o aumento da frequência de movimento (ver também CATTAERT et al. (1999).

Em uma investigação recente, TSENG e SCHOLZ (2005) avaliaram as assimetrias interlaterais de desempenho na coordenação interarticular (ombro, 
cotovelo e punho) na tarefa de desenhar círculos. Os participantes desse estudo foram avaliados realizando movimentos circulares cíclicos com ambos os braços na frequência de movimento preferida, procurando sincronizar a realização do movimento com os toques de um metrônomo. Os resultados demonstraram que o tamanho do círculo não diferiu entre os braços, mas a variabilidade do tamanho do círculo foi maior quando os movimentos foram realizados com o braço nãodominante comparado com o braço dominante. Também foi encontrada maior circularidade do movimento com o braço dominante do que com o braço nãodominante. Em relação à coordenação interarticular, foi demonstrado nesse estudo que o movimento angular relativo do cotovelo foi maior comparado ao ângulo do ombro, enquanto que o movimento angular do punho foi limitado durante a ação. Tais resultados foram consistentes tanto com o braço dominante quanto com o braço não-dominante.

Em conjunto, os resultados de pesquisa nessa sessão indicam que movimentos circulares cíclicos unimanuais apresentam assimetria intermanual com vantagem observada a favor do braço dominante. Essas assimetrias de desempenho foram detectadas principalmente em frequências mais altas de movimento. No entanto, todos os estudos encontrados que utilizaram movimentos circulares como tarefas para analisar a assimetria na coordenação de movimentos manuais avaliaram somente as estratégias de controle motor intermembros (e.g., KELSO, 1984; SEMJEN et al. 1995; SUMMERS, SEMJEN, CARSON \& THOMAS, 1995; CARSON et al. 1997; CATTAERT et al. 1999) ou analisaram de forma limitada a coordenação interarticular (e.g., TSENG \& SCHOLZ, 2005). Contudo, independentemente da proposição para explicar a vantagem do braço dominante sobre o braço não-dominante no desempenho de movimentos circulares cíclicos, ainda não são conhecidas as variações no modo de coordenação interarticular que levam à perda de circularidade de movimentos 
com o braço não-dominante principalmente quando se aumenta a velocidade de movimento.

2.2.1 Coordenação interarticular de movimentos cíclicos realizados com o braço dominante em função do aumento da velocidade de movimento.

Nesta seção serão abordados resultados de pesquisas sobre a influência da manipulação da velocidade de movimento na coordenação interarticular de movimentos cíclicos realizados com o braço dominante. Tais estudos servirão como base para o entendimento sobre assimetrias interlaterais na coordenação interarticular de movimentos circulares cíclicos unimanuais.

A manipulação da velocidade de movimento tem provado ser uma poderosa ferramenta para testar mudanças espontâneas no padrão de movimento e na estabilidade dos modos de coordenação em movimentos multi-articulares (KELSO, BUCHANAN \& WALLAC, 1991; CARSON et al., 1997; SPENCER et al., 2005). Tem sido observado que modos preferenciais de coordenação possuem baixa variabilidade das características do movimento, pela preservação do padrão de coordenação em altas velocidades de movimento ou pela transição de padrões menos estáveis para padrões mais estáveis quando se aumenta a velocidade de movimento (KELSO, 1984; SCHOLZ e KELSO, 1989, 1990, SUMMERS). Baseado nessas considerações, DOUNSKAIA, GEMMERT e STELMACH (2000) avaliaram a influência do aumento da velocidade de movimento em tarefa de desenhar círculos com o braço dominante, utilizando movimentos da articulação do punho e do dedo indicador. Os resultados demonstraram que em altas velocidades houve perda da circularidade do movimento, manifestada pela transformação da trajetória circular em uma trajetória elíptica. A análise dos movimentos do dedo e do punho durante essa 
tarefa revelou que as preferências do modo de coordenação foram relacionadas com a coordenação temporal entre os movimentos do punho e do dedo e não ao número de articulações envolvidas na realização do movimento. Isso está relacionado à constatação de que os valores de fase relativa entre os movimentos do punho e do dedo diminuíram com o aumento da velocidade de movimento, enquanto que as amplitudes do punho e dedo não foram afetadas pela manipulação da velocidade. Isto indica que, a perda da circularidade não foi causada pelo envolvimento limitado de um dos graus de liberdade, mas, resultou das mudanças no modo de coordenação entre o punho e dedo. Resultados complementares foram encontrados por DOUNSKAIA, SWINNEN, WALTER, SPAEPEN e VERSCHUEREN (1998) com manipulação da velocidade de movimento para avaliar mudanças no modo de coordenação interarticular durante movimentos cíclicos de flexão e extensão de cotovelo e punho do braço dominante em três padrões de movimento, em-fase, anti-fase e punho-livre (caracterizado pela alternância de flexão e extensão do cotovelo com o punho relaxado). Os resultados demonstraram que quando a velocidade do movimento foi aumentada, tanto movimentos em-fase quanto anti-fase perderam suas características individuais e adquiriram características do padrão punho-livre. Os autores sugeriram que a deterioração dos padrões de controle em altas velocidades de movimento seria devida à limitação no tempo disponível para o processamento de informação proprioceptiva no controle da articulação distal (punho).

DOUNSKAIA, KETCHAM e STELMACH (2002) manipularam diferentes formas de desenho, como por exemplo, círculo perfeito e elipse em diferentes direções. Estas ações foram utilizadas para estudar as características do modo de controle das articulações do ombro e do cotovelo do braço dominante durante movimentos cíclicos. Os resultados demonstraram diferentes 
funções das duas articulações na realização do movimento. O controle do ombro foi similar em todas as direções de movimento, criando uma base para todo o movimento do braço. Foi observado que a variabilidade na trajetória final do movimento foi dada pelas diferenças no controle do cotovelo, servindo como um sintonizador fino da trajetória final do movimento.

De forma geral, as estratégias de controle de coordenação interarticular de movimentos cíclicos com o braço dominante em diferentes velocidades de movimento são conhecidas, mas ainda não são conhecidas as assimetrias interlaterais na coordenação interarticular que levam à perda de circularidade de movimentos e a maior variabilidade espacial encontradas em altas velocidades de movimento quando realizado com o braço não-dominante.

\subsection{Hipótese de Dominância Dinâmica}

A dominância lateral para controle motor tem sido proposta ser devida a uma capacidade superior do membro dominante em lidar com a dinâmica do movimento. Esta conjectura foi proposta por SAINBURG (2002) como a hipótese de dominância dinâmica. Segundo essa hipótese, o sistema hemisfério cerebral esquerdo/braço direito em indivíduos destros é especializado no controle da trajetória do membro, enquanto que o hemisfério contralateral é especializado no controle da posição final do membro, em tarefa de movimentos de alcançar um alvo no espaço (SAINBURG, 2002). Esta hipótese emergiu de estudos demonstrando a superioridade do braço dominante no controle da dinâmica interarticular, conforme solicitado para especificação da trajetória da mão durante movimentos de alcançar um alvo (e.g., SAINBURG \& KALAKANIS, 2000; SAINBURG, 2002; BAGESTEIRO \& SAINBURG, 2002; SAINBURG \& WANG, 2002; WANG \& SAINBURG, 2003). 
A hipótese de dominância dinâmica teve origem em um estudo realizado por SAINBURG (2002), em que os participantes tinham que alcançar oito alvos em ambiente virtual, permitindo o uso de feedback visual somente para a posição do alvo e para a localização do dedo indicador. Esse procedimento foi conduzido em duas condições experimentais com a finalidade de investigar a influência das transformações visuomotoras versus uma nova dinâmica intersegmentar em relação ao desempenho de cada braço. Para avaliar as transformações visuomotoras, foi utilizada uma tarefa de rotação visuomotora, na qual os participantes tiveram que se adaptar a uma representação do feedback da posição do dedo modificado a $30^{\circ}$ em relação à posição inicial. Por outro lado, novas dinâmicas intersegmentares foram avaliadas usando um paradigma de adaptação da carga inercial. Após a familiarização inicial à execução do alcançar sem carga, uma carga de $1 \mathrm{~kg}$ foi adicionada ao antebraço do participante para a prática. Em seguida, a tarefa foi repetida na situação de adaptação, sem a carga inercial. Os resultados mostraram adaptação equivalente entre os dois braços às novas transformações visuomotoras, mas diferenças interlaterais para as novas adaptações dinâmicas inerciais, demonstrando maior eficiência em utilizar a ação dos músculos do braço dominante para gerar o movimento de alcançar a posiçãoalvo em comparação ao braço não-dominante. Esses achados fornecem suporte à noção de que as assimetrias interlaterais no controle do movimento surgem durante transformações visuomotoras, quando as variáveis dinâmicas que correspondem às forças necessárias para produzir o movimento são especificadas (SAINBURG, 2002).

À luz das vantagens atribuídas ao braço dominante no controle da dinâmica da trajetória do membro, foi sugerido que o braço não-dominante apresenta vantagem no controle da posição final (SAINBURG \& KALAKANIS, 2000; BAGESTEIRO \& SAINBURG, 2002, 2003; SAINBURG, 2002; 
SAINBURG \& WANG, 2002; WANG \& SAINBURG, 2003; DUFF \& SAINBURG, 2007). O suporte a essa hipótese foi fornecido originalmente por BAGESTEIRO e SAINBURG (2003), na avaliação de assimetrias interlaterais em resposta a mudanças imprevisíveis de uma carga inercial aplicada durante o movimento de alcançar um alvo. Nesse estudo um cursor virtual representando a posição final do dedo era movido para uma posição a $20^{\circ}$ de flexão do cotovelo. Em algumas tentativas, de forma inesperada pelo participante, uma massa de 2 $\mathrm{kg}$ era adicionada lateralmente ao antebraço do participante. Os resultados demonstraram que o braço não-dominante apresentou compensação de carga, sendo que nenhuma diferença significante na acurácia da posição final ocorreu entre as tentativas com e sem carga. Esta compensação da carga desconhecida acorreu no período pós-pico de velocidade, indicando uma função especializada para o braço não-dominante em correções de erros mediados por feedback sensorial. Por outro lado, o braço dominante compensou demasiadamente o efeito da carga, produzindo um amplo erro além da posição final (ultrapassagem) comparado a condição sem carga. Tais resultados sugerem que a especialização do braço dominante no controle da trajetória do membro e na dinâmica da tarefa está especificamente relacionada ao mecanismo de controle feedforward. Por meio dessa estratégia, foi demonstrado que os movimentos do braço dominante foram controlados integralmente por meio de uma sequência pré-estruturada de comandos motores, no qual a resposta motora não foi alterada mesmo com a presença de informação sensorial, levando a um erro grosseiro do desempenho (ver também BAGESTEIRO \& SAINBURG, 2002; SAINBURG, 2002; SAINBURG \& SCHAEFER, 2004; SAINBURG \& WANG, 2002; WANG \& SAINBURG, 2003; HAALAND, PRESTOPNIK, KNIGHT \& LEE, 2004; DUFF \& SAINBURG, 2007; WANG \& SAINBURG, 2007; SCHAEFER et al., 2007; SHABBOTT \& SAINBURG, 2008). 
Visto que em tarefas discretas o braço dominante apresenta melhor controle da dinâmica da trajetória do membro e o braço não-dominante apresenta melhor controle na posição final do movimento (BAGESTEIRO \& SAINBURG, 2002, 2003; SAINBURG, 2002; SAINBURG \& WANG, 2002; WANG \& SAINBURG, 2007), seria plausível supor que em movimentos circulares cíclicos em que o componente principal do movimento é a trajetória, o braço dominante em comparação ao braço não-dominante apresentasse trajetórias mais próximas àquela especificada como resultado da coordenação interarticular mais estável em comparação ao braço não-dominante. Em altas velocidades de movimento essa assimetria intermanual era esperada ser mais evidente.

\section{OBJETIVO}

Este estudo teve como objetivo avaliar assimetrias intermanuais em movimentos circulares cíclicos. A avaliação foi feita em movimentos efetuados em diferentes frequências, atingindo a velocidade máxima de movimentos com o braço não-dominante. Foram avaliados tanto aspectos métricos quanto de coordenação interarticular.

\section{JUSTIFICATIVA}

Em relação à tarefa de desenhar círculos, tem sido observado que os movimentos realizados com o braço não-dominante são mais variáveis em tamanho (FRANZ et al., 2002; TSENG \& SCHOLZ, 2005, 2006), por apresentar uma trajetória menos circular e com maior variabilidade espacial (CARSON et al., 1997; CATTAER et al., 1999; TSENG \& SCHOLZ, 2006; DOUNSKAIA et al., 2010), principalmente em altas velocidades de movimento, quando 
comparado com o braço dominante. No entanto, ainda não são conhecidas as assimetrias interlaterais de desempenho na coordenação interarticular de movimentos circulares cíclicos que levam a essas assimetrias manuais quando realizadas em alta velocidade de movimento.

\section{HIPÓTESES}

Foi hipotetizado que com o aumento da frequência de movimentos seriam observados os seguintes comportamentos apenas no braço não-dominante:

(1) Redução da circularidade de movimento.

(2) Aumento da variabilidade da circularidade de movimento.

(3) Aumento da variabilidade da fase relativa entre os movimentos nas articulações do ombro e do cotovelo.

\section{MÉTODO}

\subsection{Participantes}

Participaram do estudo 16 estudantes universitários, destros, do sexo masculino, com idades entre 19-23 anos $(M=20,06$ anos, $d p=1,53)$ e com estatura entre 1,70-1,80 m. Como critérios de exclusão não foram aceitos voluntários que possuíssem qualquer problema de saúde que comprometesse o desempenho da tarefa ou que estivessem utilizando medicamentos que interferissem na atenção ou na coordenação motora. Todos os participantes foram informados dos procedimentos do estudo e assinaram um termo de consentimento de participação livre e esclarecido. Os procedimentos do experimento foram aprovados por Comitê de Ética local. 


\subsection{Tarefa e instrumentos}

A tarefa consistiu em realizar movimentos cíclicos circulares unimanuais em diferentes frequências relativas de movimento, procurando contornar um círculo em projeção de $13 \mathrm{~cm}$ de diâmetro, fixado sobre uma placa horizontal posicionada sobre uma mesa. Os movimentos do braço foram realizados aproximadamente na altura dos ombros, com o cotovelo inicialmente flexionado, antebraço em posição neutra, punho imobilizado por uma órtese para evitar movimentos dessa articulação, e mão fechada segurando uma caneta de cor vermelha, a qual tinha que ser mantida a uma distância de aproximadamente 4 cm entre a mão e a placa horizontal, evitando assim tocar o círculo com a caneta durante o movimento. A articulação do punho foi imobilizada, pois seu envolvimento nesta tarefa é considerado pequeno (posição relativamente estável) e, a articulação do ombro e do cotovelo são as principais envolvidas nesse movimento (LACQUANITI et al., 1987, TSENG \& SCHOL, 2005). Por meio de movimentos de flexão e extensão do cotovelo e adução e abdução do ombro, o participante realizava movimentos circulares unimanuais ininterruptamente no sentido anti-horário com o braço dominante ou no sentido horário com o braço não-dominante. O objetivo da tarefa era completar cada ciclo do movimento em sincronização com cada toque produzido por um metrônomo auditivo (marca Boss, Dr Beat DB-60). Um ciclo de movimento foi considerado como uma volta completa no círculo, iniciando e terminando em um ponto demarcado. Como superfície para fixar o modelo do círculo, foi empregada uma placa horizontal de cor preta (33 cm de largura por $90 \mathrm{~cm}$ de comprimento). Essa placa foi fixada sobre uma mesa (70 cm de altura, $180 \mathrm{~cm}$ de comprimento e $33 \mathrm{~cm}$ de largura). O modelo do círculo, de cor amarela, com $13 \mathrm{~cm}$ de diâmetro e $2 \mathrm{~cm}$ de espessura, foi fixado no centro da placa preta, sendo que a parte inferior do 
círculo (posição $270^{\circ}$, parte mais próxima do tronco do participante) ficava a 10 $\mathrm{cm}$ da borda da mesa. Este posicionamento do círculo foi utilizado para todos os participantes. Um ponto preto foi desenhado na parte inferior do círculo para indicar a posição inicial do movimento (veja FIGURA 1 para ilustração do posicionamento dos instrumentos e do participante na tarefa).

a)

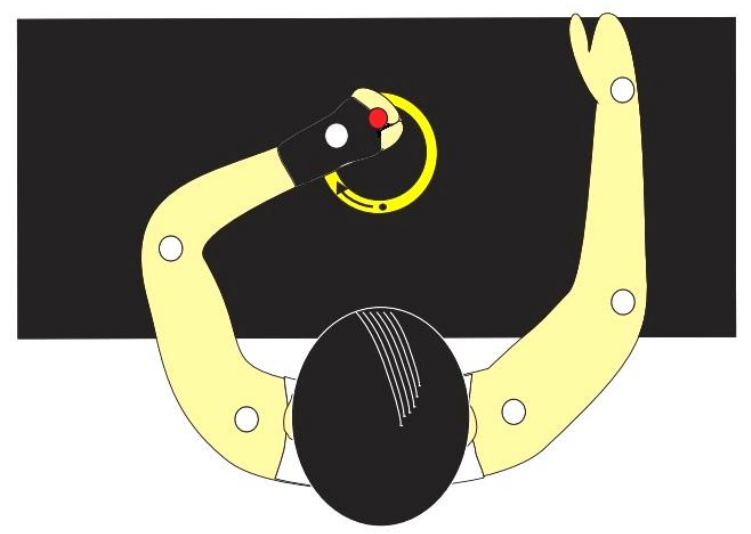

b)

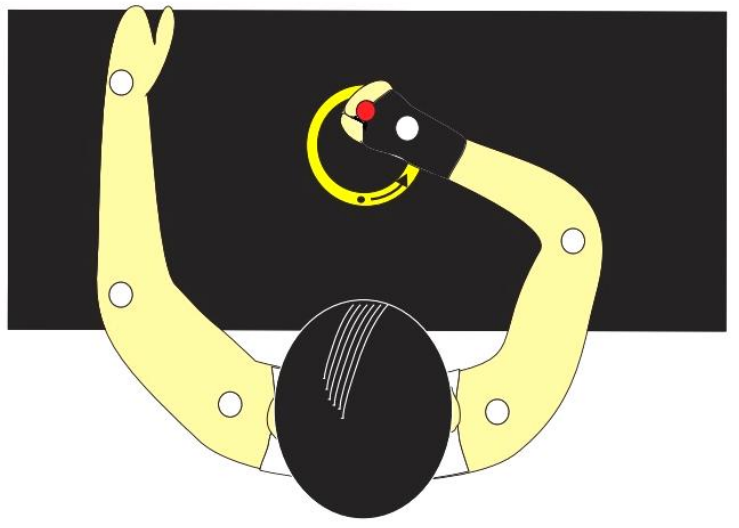

FIGURA 1 - Representação esquemática da tarefa experimental, indicando o posicionamento dos instrumentos e do participante na realização da tarefa. Figura (a), representação da tarefa com o braço nãodominante no sentido horário, e figura (b), representação da tarefa com o braço dominante no sentido anti-horário.

O participante era instruído a ficar em uma posição confortável, com o tronco ereto e apoiado posteriormente pelo encosto da cadeira, mantendo uma distância anterior de $5 \mathrm{~cm}$ da borda da mesa. Após definir a posição do tronco foi definida a posição dos braços, com a mão contrária à de execução apoiada na borda da placa horizontal e a mão de execução posicionada acima da posição inicial com o braço e o antebraço posicionados aproximadamente na altura do ombro (FIGURA 1). O apoio da mão contrária à de execução na borda da placa 
horizontal e o apoio do tronco no encosto da cadeira foram utilizados para evitar movimentos do tronco durante a realização dos movimentos manuais circulares. Embora a tarefa não requisitasse movimento do tronco, essas precauções foram tomadas para garantir que o tronco não participasse da tarefa, de modo que pudéssemos relacionar o movimento da mão aos movimentos articulares do membro superior. Um experimentador auxiliou no monitoramento dos participantes para garantir que o tronco e o deslocamento vertical do braço e antebraço permanecessem estáveis durante o experimento.

Os registros dos movimentos para posterior análise cinemática foi realizado por um sistema opto-eletrônico (Vicon, Nexus 1.4), com frequência de aquisição de dados de $240 \mathrm{~Hz}$. Três câmeras filmadoras foram posicionadas acima da base de suporte onde foi desempenhado o movimento para posterior análise planar. Seis marcadores refletivos passivos foram fixados nos membros superiores dos participantes, permitindo a construção do modelo biomecânico de cada braço e o rastreamento automático dos pontos pelo sistema durante o movimento. Os marcadores refletivos foram fixados nos seguintes pontos anatômicos dos braços direito e esquerdo: punhos (processo estilóide do rádio), cotovelos (parte superior do epicôndilo do úmero) e ombros (acrômio). A junção entre os pontos adjacentes relativos às articulações constituiu os segmentos do antebraço, do braço e do tronco. O ângulo formado entre os segmentos adjacentes determinou o ângulo do cotovelo (braço-antebraço) e o ângulo do ombro (braço-tronco). 


\subsection{Delineamento e procedimentos experimentais}

O espaço experimental foi calibrado utilizando um dispositivo de calibração, o qual é constituído por 5 marcadores refletivos fixados em uma haste com formato da letra $\mathrm{T}$. Este dispositivo foi posicionado primeiramente de forma estática e depois de forma dinâmica na área onde o movimento é realizado. Os eixos $x$ e $y$ são as coordenadas planas, enquanto que o eixo $z$ é a diferença de altura entre os marcadores e o ponto de origem do sistema.

Os procedimentos experimentais foram realizados em dois dias (ver TABELA 1 para síntese). O primeiro dia destinou-se a estimar a frequência máxima de movimento que cada participante conseguia realizar a tarefa. Inicialmente os participantes eram informados dos procedimentos experimentais e assinavam o termo de consentimento de participação livre e esclarecido. Para avaliar a preferência manual dos participantes foi aplicado o Inventário de Dominância Manual de Edimburgo (OLDFIELD, 1971; APÊNDICE I). Em seguida, foram fixados marcadores refletivos no punho direito e esquerdo para serem rastreados e registrados para subsequente análise da estimativa média da máxima velocidade de movimento. Cada participante realizou três tentativas na tarefa experimental com máxima velocidade, com os braços dominante e nãodominante alternadamente. O intervalo entre tentativas foi de 2 min. Cada tentativa consistiu na realização de 15 ciclos de movimento com cada braço. A contagem dos ciclos foi monitorada por um experimentador auxiliar. A partir da média da máxima velocidade de cada braço foi identificada a menor média máxima da velocidade alcançada com um dos braços, a qual foi utilizada como base para determinar as demais frequências relativas de movimento, tanto para o braço dominante quanto para o não-dominante. As frequências relativas de movimento foram determinadas da seguinte forma: início em $40 \%$ da máxima 
velocidade e degraus progressivos de $15 \%$, totalizando cinco velocidades de movimento, sendo: $40 \%, 55 \%, 70 \%, 85 \%$ e $100 \%$ da máxima velocidade.

O segundo dia foi destinado à realização das cinco frequências relativas de movimento com cada braço. Marcadores refletivos foram fixados em regiões específicas do membro superior do participante. Em seguida, duas tentativas de familiarização e três tentativas experimentais foram realizadas em cada frequência relativa de movimento tanto com o braço dominante quanto com o braço não-dominante. As tentativas de familiarização tiveram como objetivo introduzir o participante à tarefa, de forma a proporcionar-lhe plena compreensão do objetivo da tarefa e atenuar a variabilidade das tentativas iniciais, conferindo assim maior representatividade aos valores observados nas tentativas válidas para registro. As instruções para a realização da tarefa foram dadas verbalmente, enfatizando-se a importância de se tentar contornar o círculo projetado da melhor forma possível e sincronizar cada ciclo de movimento com a frequência dada pelo metrônomo. Antes de iniciar o movimento, o metrônomo e o sistema optoeletrônico eram ligados, e passados $5 \mathrm{~s}$ o experimentador dava um sinal verbal para que o participante iniciasse o movimento. Em todas as frequências relativas de movimento eram completados 15 ciclos de movimento. Caso o participante tocasse a caneta na placa horizontal ou deslocasse verticalmente o braço e o antebraço ou ainda desencostasse o tronco do encosto da cadeira durante a ação, a tentativa era cancelada e imediatamente repetida. A quantidade de ciclos de movimento e a sincronização entre o tempo de ciclo do movimento realizado e a frequência do metrônomo foram controladas e monitoradas visualmente por um experimentador auxiliar. $\mathrm{O}$ tempo de movimento da tarefa variou conforme o tempo necessário para realizar aproximadamente 15 ciclos de movimento em cada frequência de movimento. A fim de prevenir fadiga, era dado um intervalo de repouso de aproximadamente 1 min. entre as tentativas. Metade dos 
participantes iniciou a avaliação com o braço dominante e a outra metade com o braço não-dominante. A ordem das frequências relativas de movimento foi pseudo-aleatorizada entre os participantes.

TABELA 1 - Síntese do delineamento e procedimentos experimentais

\section{$1^{\circ}$ Dia de Coleta de Dados}

Objetivo: Estimar a frequência máxima de movimento

1. Aplicação do Inventário de Dominância Lateral

2. Explicação da tarefa

3. Fixação dos marcadores refletivos no punho direito e esquerdo

4. Realização da tarefa - três tentativas com máxima velocidade com o braço dominante e com o braço não-dominante

5. Cálculo das outras quatro frequências de movimento baseada na menor média máxima da velocidade alcançada com um dos braços

\section{$2^{\circ}$ Dia de Coleta de Dados}

Objetivo: Realização das cinco frequências de movimento com cada braço aleatoriamente

1. Explicação da tarefa

2. Fixação dos marcadores refletivos em cada braço

3. Realização da tarefa - duas tentativas de familiarização e três tentativas experimentais, totalizando cinco tentativas em cada frequência de movimento

\subsection{Análise dos dados}

As variáveis dependentes foram extraídas empregando-se o programa MATLAB 7.9.0. A posição linear espacial dos marcadores foi utilizada para determinar os ângulos das articulações do ombro e do cotovelo. Os dados de 
posição foram filtrados para o cálculo posterior das variáveis dependentes. Para atenuar os ruídos na análise cinemática, foi aplicado um filtro recursivo do tipo Buterworth passa-baixa de $4^{\mathrm{a}}$ ordem; e frequência de corte de $10 \mathrm{~Hz}$. O início do movimento foi determinado pelo primeiro valor de deslocamento do eixo $x$ do punho 15 desvios padrão acima da média do limiar basal com valores subsequente superiores.

Para analisar o desempenho foram utilizados 10 ciclos sequenciais do movimento em cada frequência, descartando os dois primeiros e os três últimos ciclos de movimento. Esses ciclos de movimento foram descartados para atenuar a variabilidade inicial e final do movimento. Os valores de cada participante foram obtidos pelo cálculo da média dos 10 ciclos em cada tentativa, seguido pelo cálculo da média das três tentativas em cada condição experimental, para tratamento estatístico.

6.5 Variáveis dependentes do estudo

O desempenho na tarefa foi analisado por meio das variáveis descritas abaixo.

Erro espacial

O cálculo do erro espacial foi feito por meio da seguinte equação:

$$
\mathrm{Ee}=\left|\underline{\left(130-\mathrm{d}_{1}\right)|+|\left(130-\mathrm{d}_{2}\right)}\right|
$$

na qual, d1 é o semi-eixo maior e d2 é o semi-eixo menor. 


\section{Erro Temporal}

Foi calculada a diferença entre a frequência do metrônomo e a frequência de ciclo do movimento ciclo a ciclo e em seguida a média para cada tentativa. Valores negativos indicam adiantamento do movimento em relação à frequência do metrônomo.

Variabilidade do erro temporal

A variabilidade do erro temporal de movimentos ao longo de uma série foi calculada pelo desvio padrão dos intervalos de tempo de cada ciclo de movimento, estabelecido com base nos picos de deslocamento angular na articulação do punho.

Circularidade do movimento

O cálculo do índice de circularidade dos movimentos foi feito por meio da razão do semi-eixo menor pelo semi-eixo maior da elipse. Desta forma, o círculo ideal é indicado por uma razão igual a 1, enquanto que valores mais próximos a zero indicaram movimentos de baixa magnitude no semi-eixo de menor amplitude.

Os semi-eixos foram calculados da seguinte forma:

A partir das coordenadas $x$ e $y$ do marcador de punho, foram determinados os parâmetros de uma elipse de acordo com a equação 1 .

$a x^{2}+2 b x y+c y^{2}+2 d x+2 f y+g=0$ 
Com,

$$
\begin{aligned}
\Delta & =\left|\begin{array}{lll}
a & b & d \\
b & c & f \\
d & f & g
\end{array}\right| \\
J & =\left|\begin{array}{ll}
a & b \\
c & d
\end{array}\right| \\
I & =\mathrm{a}+\mathrm{c},
\end{aligned}
$$

e $\Delta \neq 0, J>0$, e $\Delta / I<0$. Neste caso, o centro da elipse $\left(x_{0,} y_{0}\right)$ é dado por:

$$
\begin{aligned}
& x_{0}=\frac{c d-b f}{b^{2}-a c} \\
& y_{0}=\frac{a f-b d}{b^{2}-a c}
\end{aligned}
$$

O comprimento dos semi-eixos são:

$$
\begin{aligned}
& a^{\prime}=\sqrt{\frac{2\left(a f^{2}+c d^{2}+g b^{2}-2 b d f-a c g\right)}{\left(b^{2}-a c\right)\left[\sqrt{(a-c)^{2}+4 b^{2}-(a+c)}\right]}} \\
& b^{\prime}=\sqrt{\frac{2\left(a f^{2}+c d^{2}+g b^{2}-2 b d f-a c g\right)}{\left(b^{2}-a c\right)\left[-\sqrt{(a-c)^{2}+4 b^{2}-(a+c)}\right]}}
\end{aligned}
$$


e, o ângulo de rotação do eixo $x$ para o semi- eixo maior da elipse é:

$$
\theta=\left\{\begin{array}{cl}
0 & \text { para } b=0 \text { e } a<c \\
\frac{1}{2} \pi & \text { para } b=0 \text { e } a>c \\
\frac{1}{2} \cot ^{-1}\left(\frac{a-c}{2 b}\right) & \text { para } b \neq 0 \text { e } a<c \\
\frac{\pi}{2}+\frac{1}{2} \cot ^{-1}\left(\frac{a-c}{2 b}\right) &
\end{array}\right.
$$

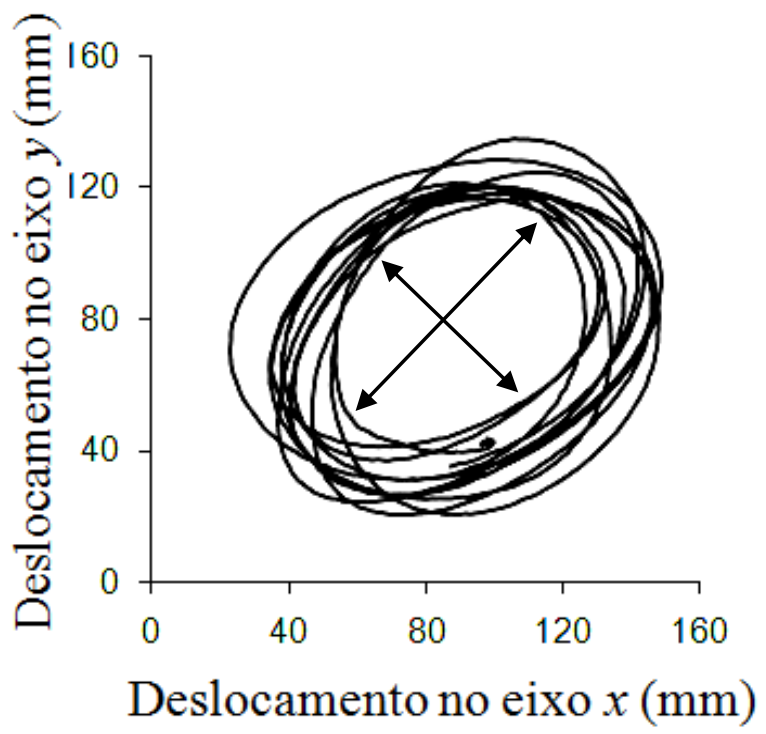

FIGURA 2 - Representação da circularidade da trajetória produzida durante o deslocamento linear do marcador do punho nos eixos $x$ e $y$ em uma tentativa. Setas no interior do círculo indicam o semi-eixo menor e o semi-eixo maior da elipse.

Variabilidade da circularidade

A variabilidade da circularidade do movimento foi calculada por meio do desvio padrão do índice de circularidade encontrado ciclo a ciclo durante a execução da ação. 
Amplitudes angulares do ombro e cotovelo

Amplitude de deslocamento angular se refere à distância entre um vale e um pico adjacentes da curva de posição para cada articulação. As amplitudes angulares do ombro e do cotovelo foram calculadas a partir da média das diferenças entre o maior e o menor valor de deslocamento angular em cada ciclo de movimento (FIGURA 3).

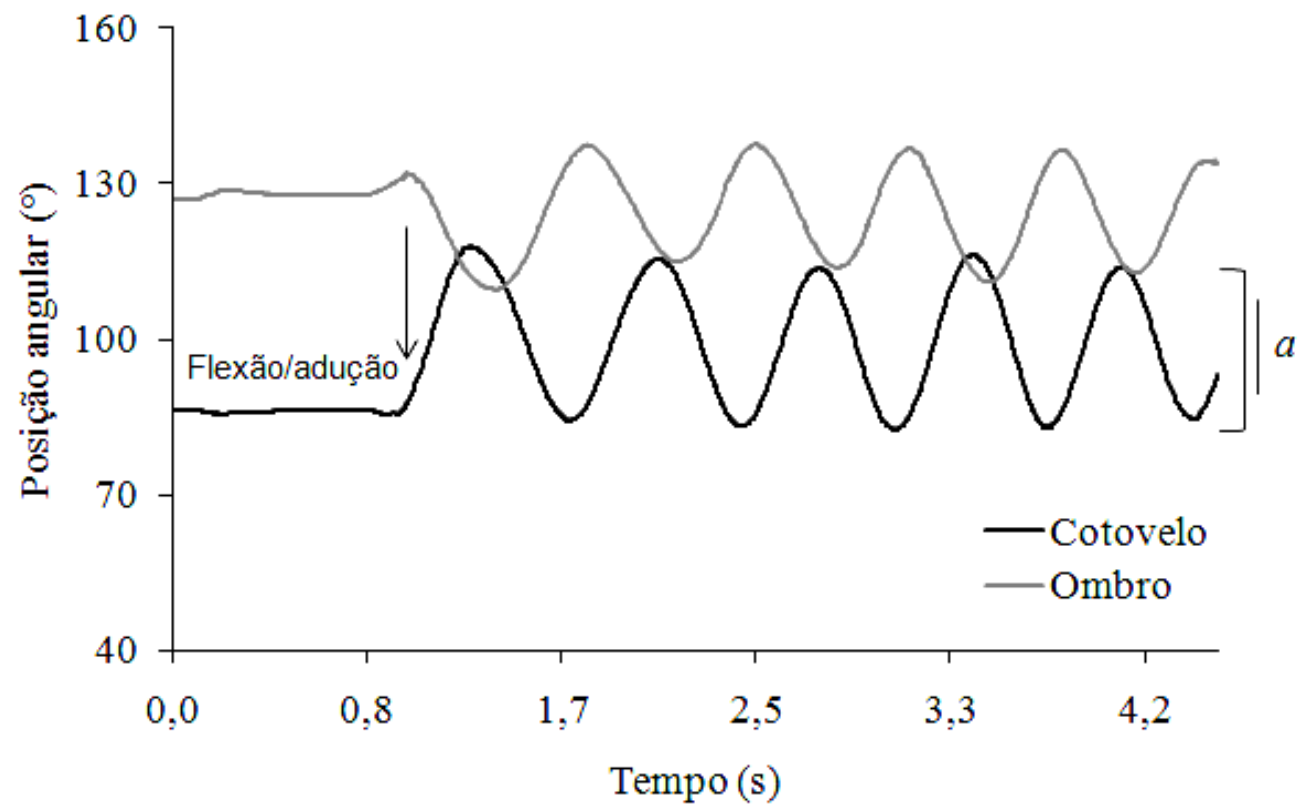

FIGURA 3 - Representação do deslocamento angular do ombro e do cotovelo durante movimentos circulares do braço dominante. A letra $a$ indica a amplitude angular na articulação do cotovelo. A seta vertical indica o sentido de flexão do cotovelo e adução do ombro. 
Variabilidade das amplitudes angulares do ombro e cotovelo

A variabilidade da amplitude angular do ombro e do cotovelo foi calculada pelo desvio padrão dos valores da amplitude angular observados durante a execução da ação.

Coeficiente de amplitude ângulo-ângulo

Para obter um índice de relação espacial de amplitude angular do ombro e cotovelo durante todo o movimento, foi calculado o coeficiente ângulo-ângulo, dado pela razão da menor pela maior amplitude dos deslocamentos angulares do ombro e do cotovelo em cada ciclo. Esta medida foi utilizada para complementar a análise da amplitude angular do ombro e cotovelo, indicando a participação de cada articulação durante os movimentos. Esta variável indica que, se cada articulação participasse igualmente na realização dos movimentos, encontraremos uma razão igual a 1, enquanto que valores mais próximos a zero indicam movimentos realizados predominantemente pela articulação do cotovelo

Variabilidade da relação ângulo-ângulo

Para cálculo da variabilidade da relação ângulo-ângulo, foi utilizado o método da variabilidade da curva-média (SIDAWAY, HEISE e SCHOENFELDER-ZOHDI, apud STERGIOU, 2004, página 54). Para tanto, foi calculada a média das séries temporais de 10 ciclos de movimento da variável deslocamento angular tanto do ombro quanto do cotovelo, utilizando a equação 1:

$$
M_{i}=\frac{\sum_{j=1}^{n} x_{i j}}{n}
$$


em que, $M_{i}$ é a média das séries temporais ou do ombro, ou do cotovelo, no $i$ ésimo instante no tempo; $x_{i j}$ é o deslocamento angular do ombro ou do cotovelo no $i$-ésimo instante no tempo do j-ésimo ciclo de movimento; e $n$ é o número de ciclos de movimento em uma tentativa. A média de cada série de dados do ombro e do cotovelo foi utilizada para criar o gráfico ângulo-ângulo. Em uma segunda etapa, foi calculado o desvio resultante bi-dimensional entre os valores de um ciclo individual e o valor da média de múltiplos ciclos para cada instante no tempo e para cada ciclo de movimento, como mostrado na equação 2 :

$$
R_{i j}=\left(\left(x_{i j}-M x_{i}\right)^{2}+\left(y_{i j}-M y_{i}\right)^{2}\right)^{1 / 2}
$$

em que, $R_{i j}$ é o desvio resultante no i-ésimo instante no tempo do j-ésimo ciclo de movimento; $x_{i j}$ e $y_{i j}$ são os valores dos dados no $i$-ésimo instante no tempo do j-ésimo ciclo para os dados de deslocamento angular do cotovelo e do ombro, respectivamente; e $M x_{i}$ e $M y_{i}$ são os valores correspondentes da média de múltiplos ciclos no i-ésimo instante no tempo.

Em uma terceira etapa foi calculado o desvio da raiz quadrada média (RMS) para cada ciclo, como mostrado na equação 3:

$$
R M S_{j}=\left(\frac{\sum_{i=1}^{K} R_{i j}^{2}}{k}\right)^{1 / 2}
$$

em que, $R M S_{j}$ é o desvio da RMS para o j-ésimo ciclo de movimento ou do deslocamento angular do ombro ou do cotovelo; $R_{i j}$ é desvio resultante para o $i$ ésimo instante no tempo do j-ésimo ciclo de movimento; e $k$ é a quantidade de 
amostras. Na quarta etapa, foi calculada a média dos valores de RMS por meio de todos os ciclos de movimento, como mostrado na equação 4:

$$
R M S_{\text {avg }}=\frac{\sum_{j=1}^{n} R M S_{j}}{n}
$$

em que, $R M S_{\text {avg }}$ é o RMS médio dos múltiplo ciclos de movimento; $R M S_{j}$ é o valor de RMS para o j-ésimo ciclo de movimento; e $n$ é o número de ciclos de movimento em cada tentativa.

Por fim, em uma quinta etapa, foi normalizado o valor de $R M S_{\text {avg }}$ para a excursão resultante da média do gráfico ângulo-ângulo sobre um ciclo completo, como mostrado na equação 5:

$$
R M S_{N}=\frac{R M S_{\text {avg }}}{L}
$$

em que, $R M S_{N}$ é o valor de RMS normalizado; $R M S_{\text {avg }}$ é a média de RMS dos múltiplo ciclos de movimento; e L é a distância resultante da curva média do gráfico ângulo-ângulo.

Fase relativa (FR)

Variável relacional de marcos cinemáticos de interesse, indicadora do padrão de coordenação interarticular em cada braço. Essa variável foi calculada por meio da razão do tempo do pico de flexão do cotovelo pelo tempo do ciclo de adução do ombro, multiplicado por 360 para se obter o resultado em graus (coordenadas polares).

$$
\mathrm{FR}=(\mathrm{b} / \mathrm{a}) \times 360
$$


em que $b$ corresponde ao momento de ocorrência do pico de flexão do cotovelo em relação ao mesmo ciclo de flexão do ombro e $a$ corresponde ao tempo de duração do ciclo do ombro (FIGURA 4).

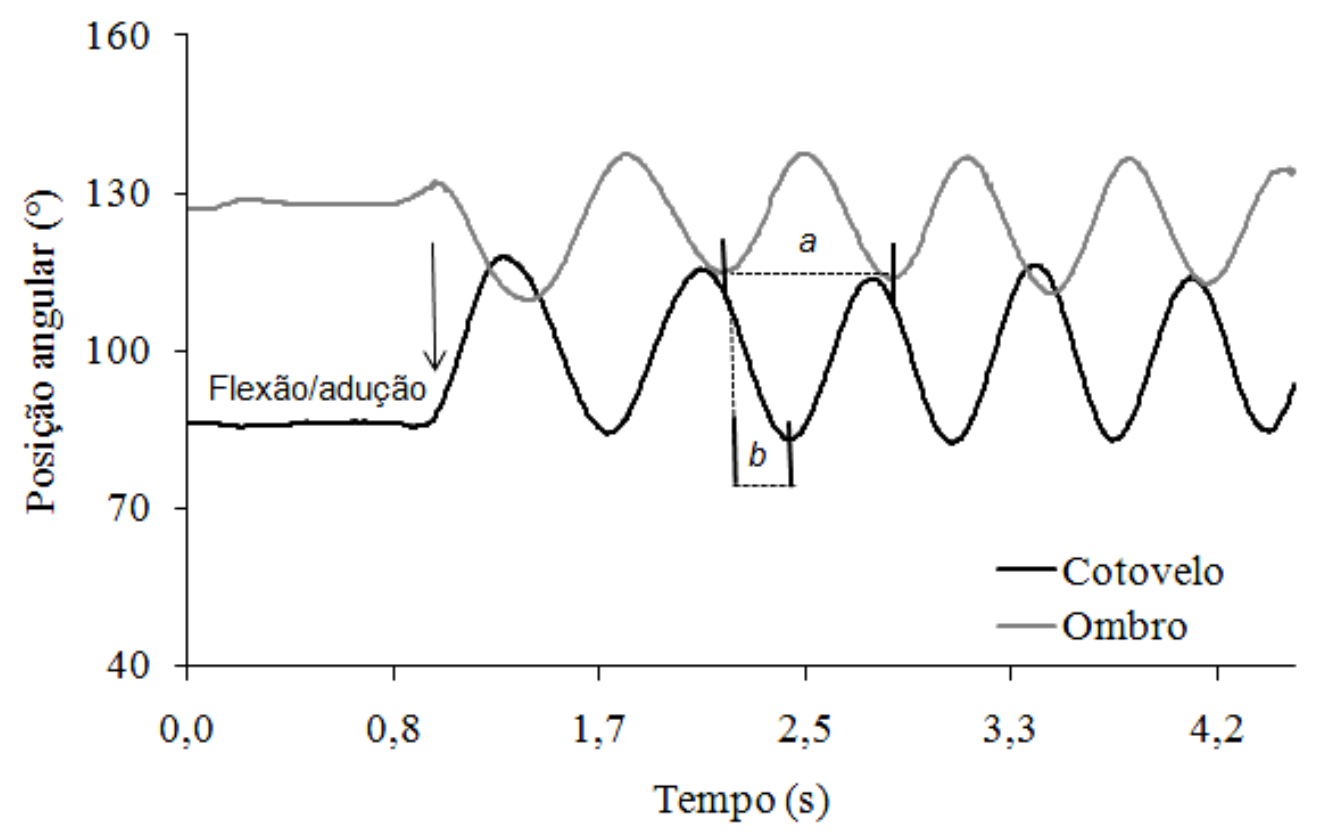

FIGURA 4 - $\quad \underline{\text { Representação do deslocamento angular do ombro e do cotovelo }}$ durante movimentos circulares do braço, com indicação dos intervalos usados para calcular a fase relativa.

Variabilidade da fase relativa

Esta variável indicadora da estabilidade do modo de coordenação foi calculada por meio do desvio padrão dos valores intra-individuais da fase relativa. 


\subsection{Análise estatística}

Foram testadas as exigências de normalidade da distribuição dos dados através do teste Shapiro-Wilk. A estatística inferencial foi utilizada para comparação entre as diferentes condições experimentais por meio de análises de variância de dois fatores 2 (braço) x 5 (frequência), com medidas repetidas em ambos os fatores, utilizando o programa Statistica. A identificação das diferenças entre os níveis dos fatores da análise foi realizada através do teste de Tukey. O nível de significância foi estabelecido em $5 \%$.

\section{RESULTADOS}

O teste Shapiro-Wilk indicou que em geral os valores estão dentro de uma distribuição normal. A média da frequência máxima observada para o braço nãodominante foi de $4,04 \mathrm{~Hz}$ e para o braço dominante foi de 4,80 Hz. As frequências relativas de movimento foram determinadas com base na média da menor velocidade máxima alcançada entre os braços; todos os participantes apresentaram média da menor velocidade máxima com o braço não-dominante. A Tabela 2 mostra à média e erro padrão da frequência relativa dos movimentos $(\mathrm{Hz})$ nas cinco frequências de movimento. A média do coeficiente de lateralidade dos participantes foi de $74 \%(d p=23,01)$, sendo que o menor valor observado foi de $47,4 \%$. 
TABELA 2 - Média e erro padrão da frequência de movimentos (Hz) nas cinco frequências avaliadas

\begin{tabular}{lccccc}
\hline & \multicolumn{5}{c}{ Frequência de Movimento (\%) } \\
\cline { 2 - 6 } & 40 & 55 & 70 & 85 & 100 \\
\hline Média & 1,62 & 2,22 & 2,83 & 3,44 & 4,04 \\
dp & 0,22 & 0,31 & 0,39 & 0,47 & 0,55 \\
\hline
\end{tabular}

Os resultados relativos a cada variável dependente são apresentados a seguir.

Erro espacial

A análise do erro espacial não detectou efeito principal significante para o fator braço, $F_{1,15}=2,25$, e para interação, $F_{4,60}=0,88$. A análise revelou efeito significante para frequência, $F_{4,60}=7,09 ; p<0,0001$. As comparações post hoc indicaram que este efeito foi devido ao maior erro espacial nas três últimas frequências em comparação com a primeira frequência de movimento (FIGURA $5)$. 


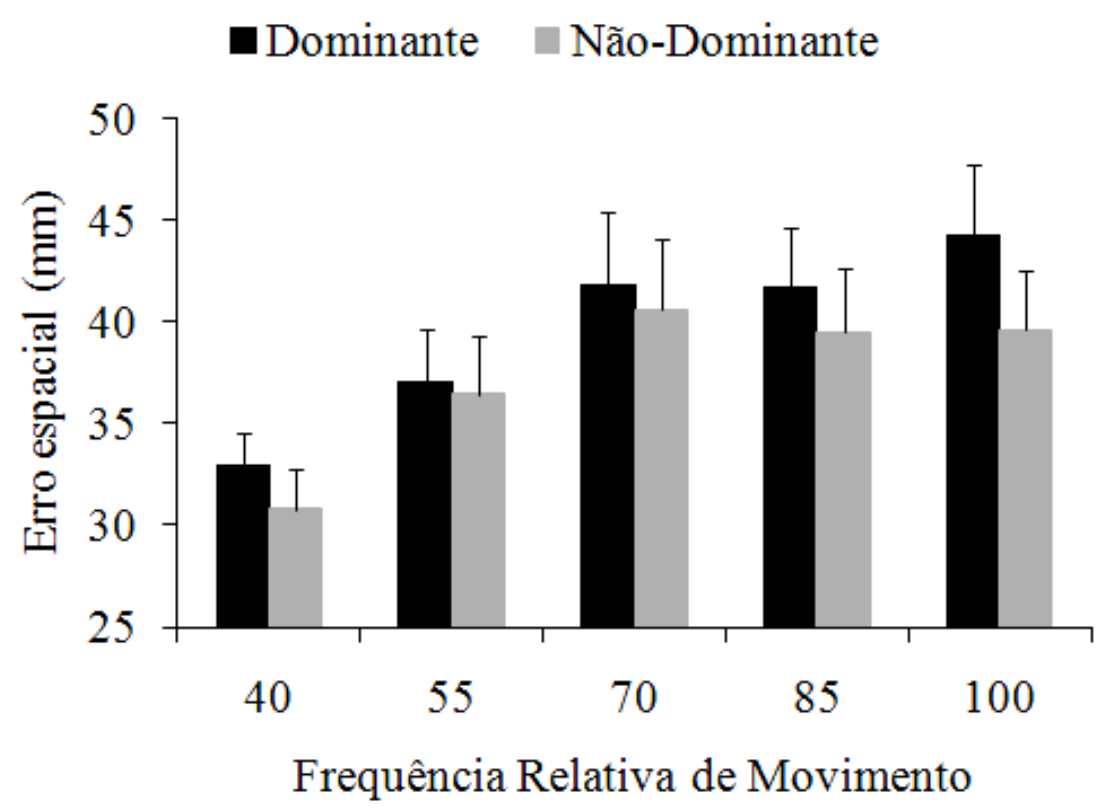

FIGURA 5 - Médias e erros-padrão (traços verticais) do erro espacial (mm) dos braços dominante e não-dominante em função da frequência relativa de movimento.

Erro temporal

A análise do erro temporal revelou efeitos principais significantes para os fatores braço, $F_{1,15}=10,46 ; p<0,01$, resultante de frequência real de movimentos mais elevada do que a frequência do metrônomo para o braço dominante $(M=$ 7,41 ms; braço não-dominante, $M=0,06 \mathrm{~ms}$ ); e frequência, $F_{4,60}=8,01$; $p<0,0001$. Comparações posteriores indicaram que houve frequência real de movimentos mais elevada nas três primeiras frequências em comparação com as duas últimas frequências. Não foi encontrada interação significante, $F_{4,60}=1,11$. (FIGURA 6). 


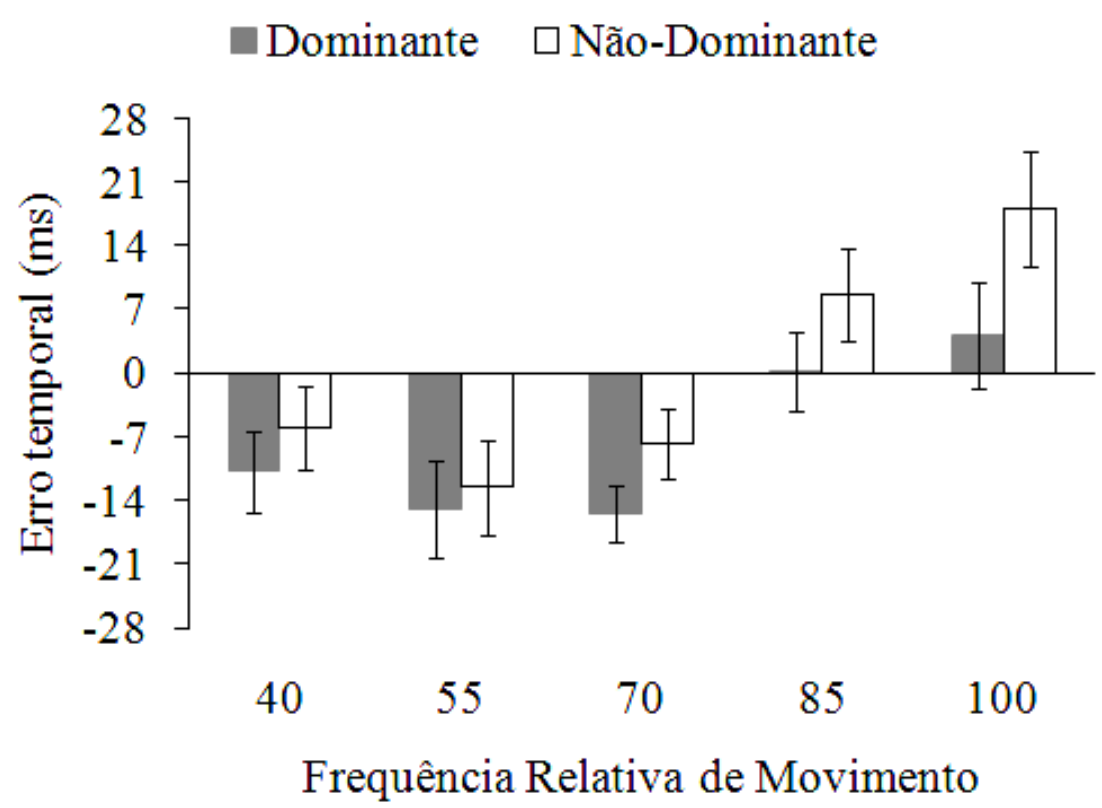

FIGURA 6 - Médias e erros-padrão (traços verticais) do erro temporal (ms) do braço dominante e do braço não-dominante em função da frequência relativa de movimento.

Variabilidade do erro temporal

A Figura 7 mostra a variabilidade do erro temporal do braço dominante e não-dominante nas diferentes condições experimentais. A análise estatística demonstrou efeito principal significante para os fatores braço, $F_{1,15}=8,06$; $p<0,01$, em função da maior variabilidade do erro temporal para o braço nãodominante $(M=18,72 \mathrm{~ms}$; braço dominante, $M=17,42 \mathrm{~ms})$; e frequência, $F_{4,60}=$ 42,$58 ; p<0,0001$. Comparações posteriores indicaram maior variabilidade do erro temporal nas três frequências mais baixas em comparação com a frequência mais alta de movimentos. Não foi detectada interação significante, $F_{4,60}=1,04$. 


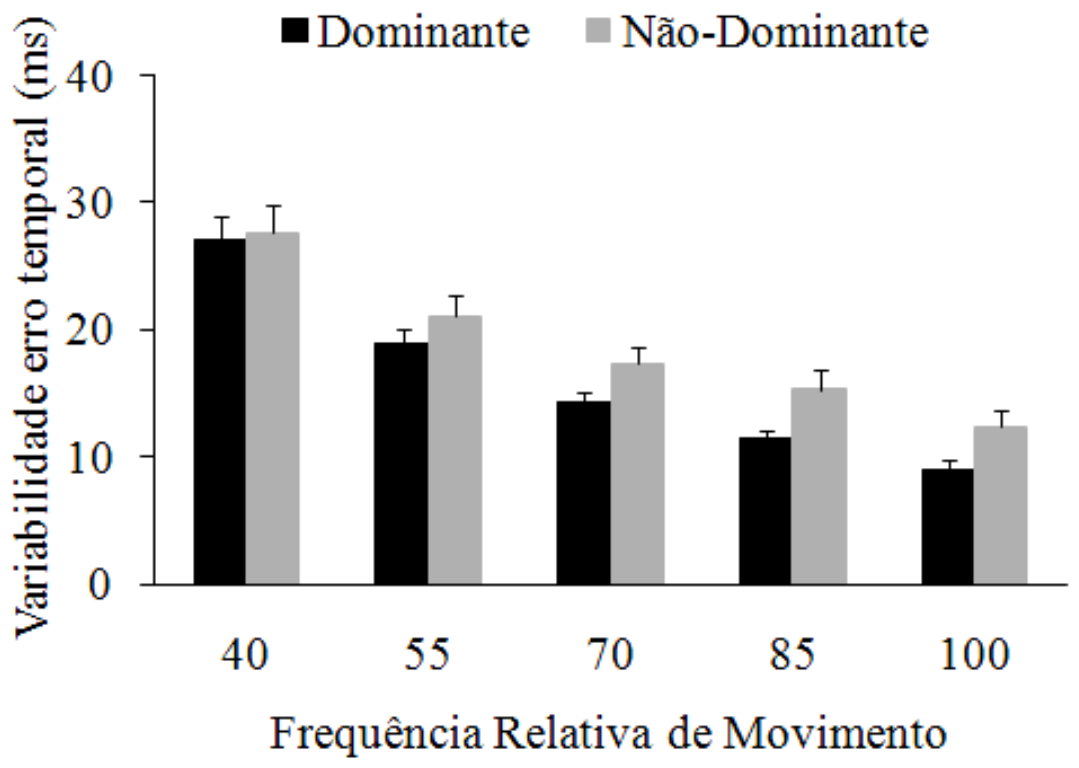

FIGURA 7 - Médias e erros-padrão (traços verticais) da variabilidade do erro temporal do braço dominante e do braço não-dominante em função da frequência relativa de movimento.

Circularidade do movimento

A análise do índice de circularidade revelou efeito principal significante para os fatores braço, $F_{1,15}=20,60 ; p<0,0001$, decorrente de menores valores do braço não-dominante $(M=0,70$; braço dominante, $M=0,78)$; e frequência, $F_{4,60}$ $=5,88 ; p<0,0001$. Comparações posteriores indicaram valor menor na última frequência em comparação com as duas primeiras frequências de movimento. A análise apontou também interação significante, $F_{4,60}=8,53 ; p<0,0001$. As comparações posteriores indicaram que o efeito foi devido a valores menores do braço não-dominante nas duas últimas frequências de movimento em comparação ao braço dominante, mas não nas demais frequências. Além disso, o braço não-dominante atingiu valores significantemente menores na última frequência em comparação com as três primeiras frequências de movimento e, 
nas três últimas frequências comparada à primeira, enquanto que nenhuma diferença foi detectada entre frequências para o braço dominante (FIGURA 8).

A Figura 9 apresenta um perfil individual representativo da trajetória dos movimentos cíclicos circulares com os braços não-dominante e dominante em diferentes frequências relativas de movimento.

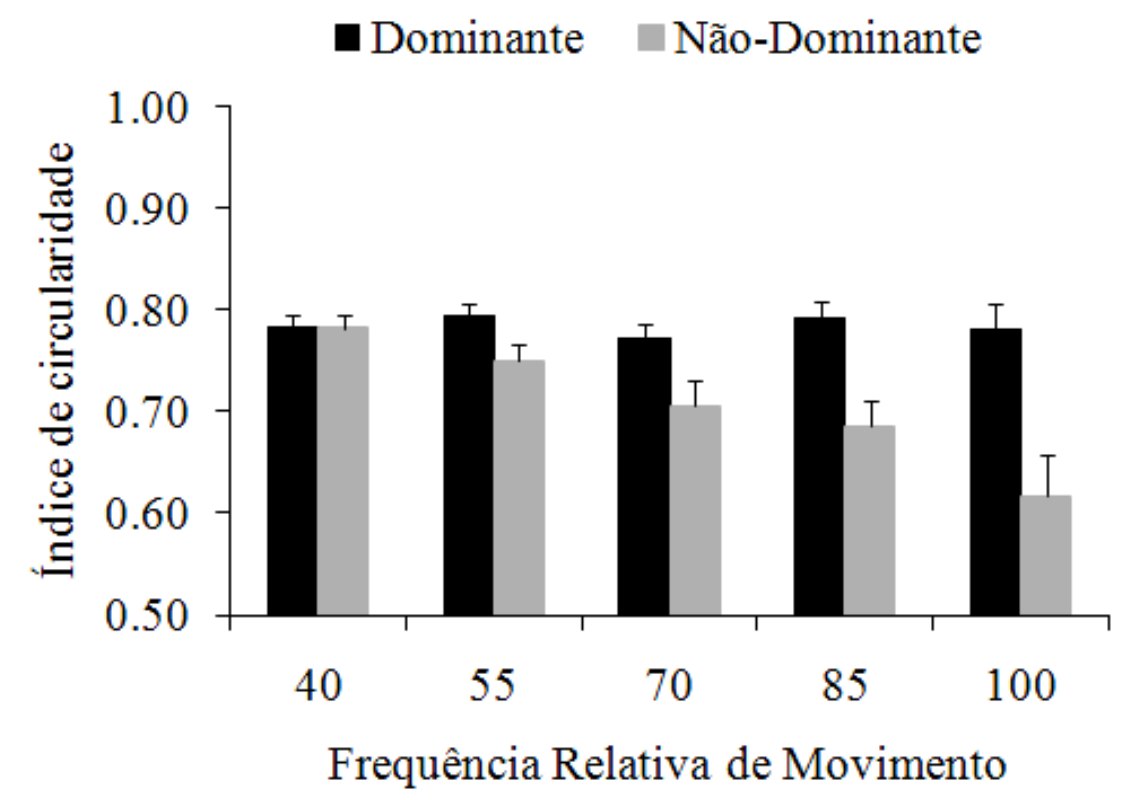

FIGURA 8 - Médias e erros-padrão (traços verticais) do índice de circularidade do movimento dos braços dominante e não-dominante em função da frequência relativa de movimento. 

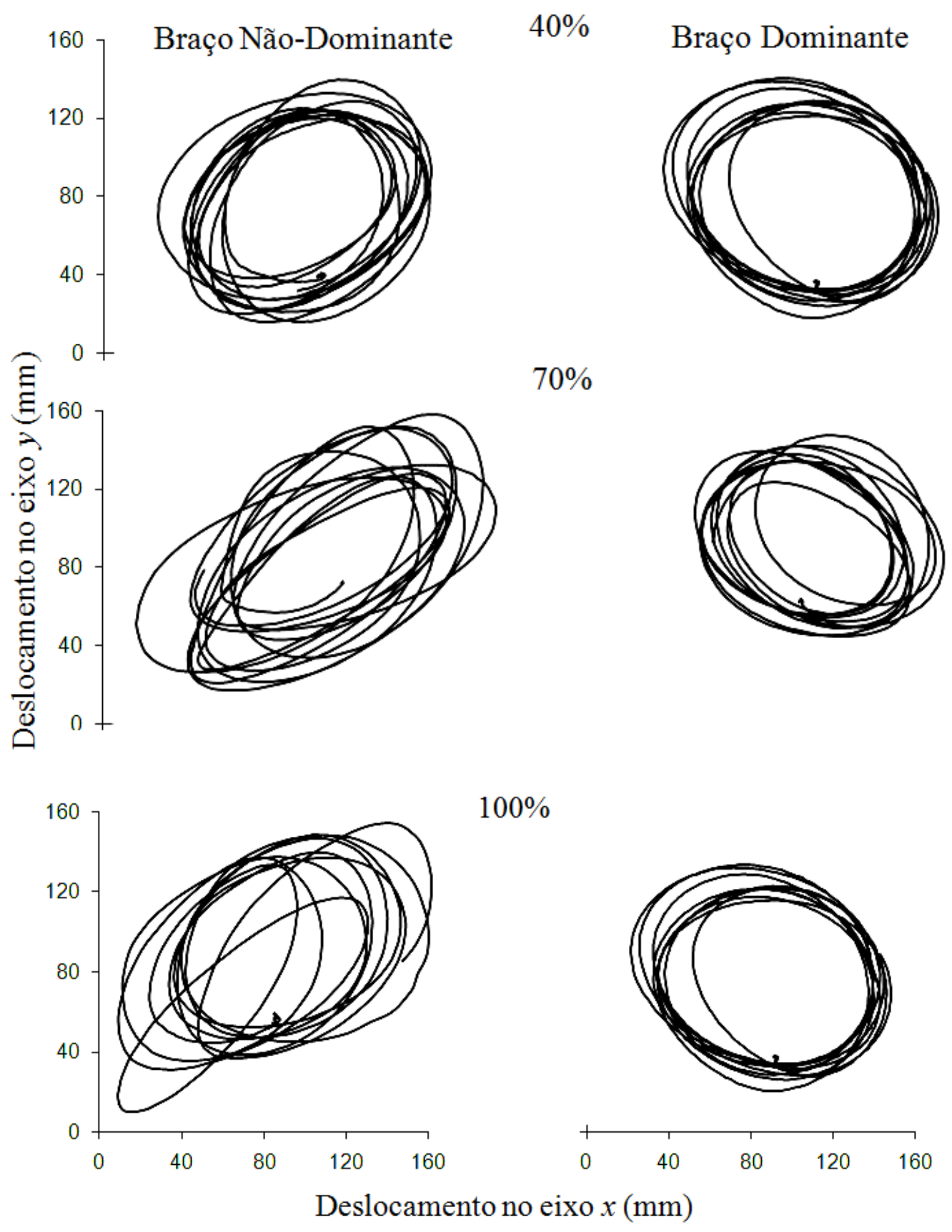

FIGURA 9 - Trajetória dos movimentos circulares produzida com o braço nãodominante e braço dominante por um participante em diferentes frequências relativas de movimento. 
Variabilidade da circularidade

A análise de variabilidade da circularidade apresentou efeito principal significante para os fatores braço, $F_{1,15}=31,97 ; p<0,0001$, em função da menor variabilidade da circularidade para o braço dominante $(M=0,07$; braço nãodominante, $M=0,09$ ); e frequência $F_{4,60}=12,37 ; p<0,0001$. Comparações posteriores indicaram maior variabilidade nas três últimas frequências em comparação com as duas primeiras, e entre as duas últimas em comparação a segunda frequência de movimento. A análise apontou interação significante $F_{4,60}$ $=2,29 ; p<0,05$. Comparações posteriores indicaram que o braço não-dominante apresentou maior variabilidade apenas nas últimas quatro frequência de movimento em comparação com o braço dominante. Além disso, o braço nãodominante atingiu valores significantemente mais elevados nas três últimas frequências em comparação a primeira frequência de movimento, enquanto que nenhuma diferença entre frequências foi detectada para o braço dominante (FIGURA 10). 


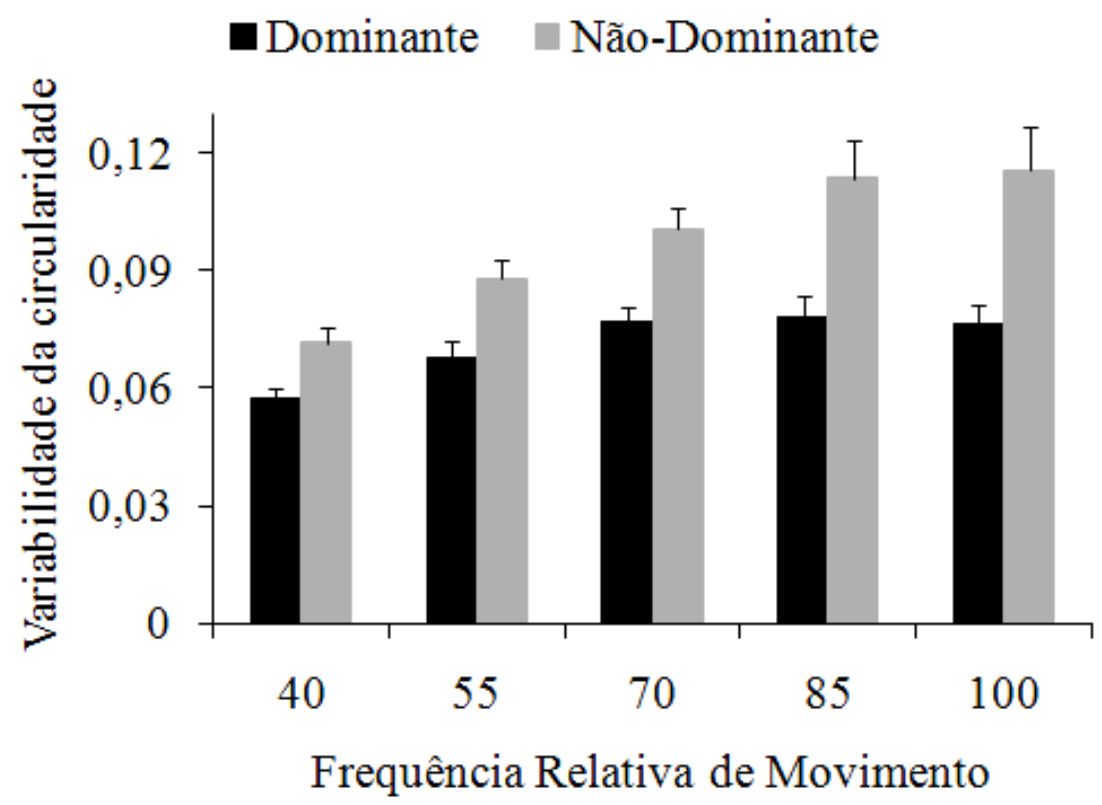

FIGURA 10 - Médias e erros-padrão (traços verticais) da variabilidade da circularidade do movimento dos braços dominante e nãodominante em função da frequência relativa de movimento.

Amplitudes angulares do ombro e cotovelo

A análise da amplitude angular do ombro não indicou efeitos significantes para os fatores principais: braço, $F_{1,15}=0,53$; frequência, $F_{4,60}=0,25$. A interação também não atingiu significância, $F_{4,60}=0,63$. Para amplitude angular do cotovelo, a análise estatística revelou efeito principal significante para o fator braço, $F_{1,15}=78,42 ; p<0,0001$, em função da maior amplitude angular para 0 braço não-dominante $\left(M=40,13^{\circ}\right.$; braço dominante, $\left.M=25,33^{\circ}\right)$, mas não para o fator frequência, $F_{4,60}=0,29$. A análise revelou efeito significante para interação, $F_{4,60}=3,14 ; p<0,02$. Comparações posteriores indicaram que o braço nãodominante apresentou maior amplitude angular na primeira frequência em comparação com a última frequência de movimento, enquanto que nenhuma 
diferença entre frequências foi detectada para o braço dominante (FIGURA 11).

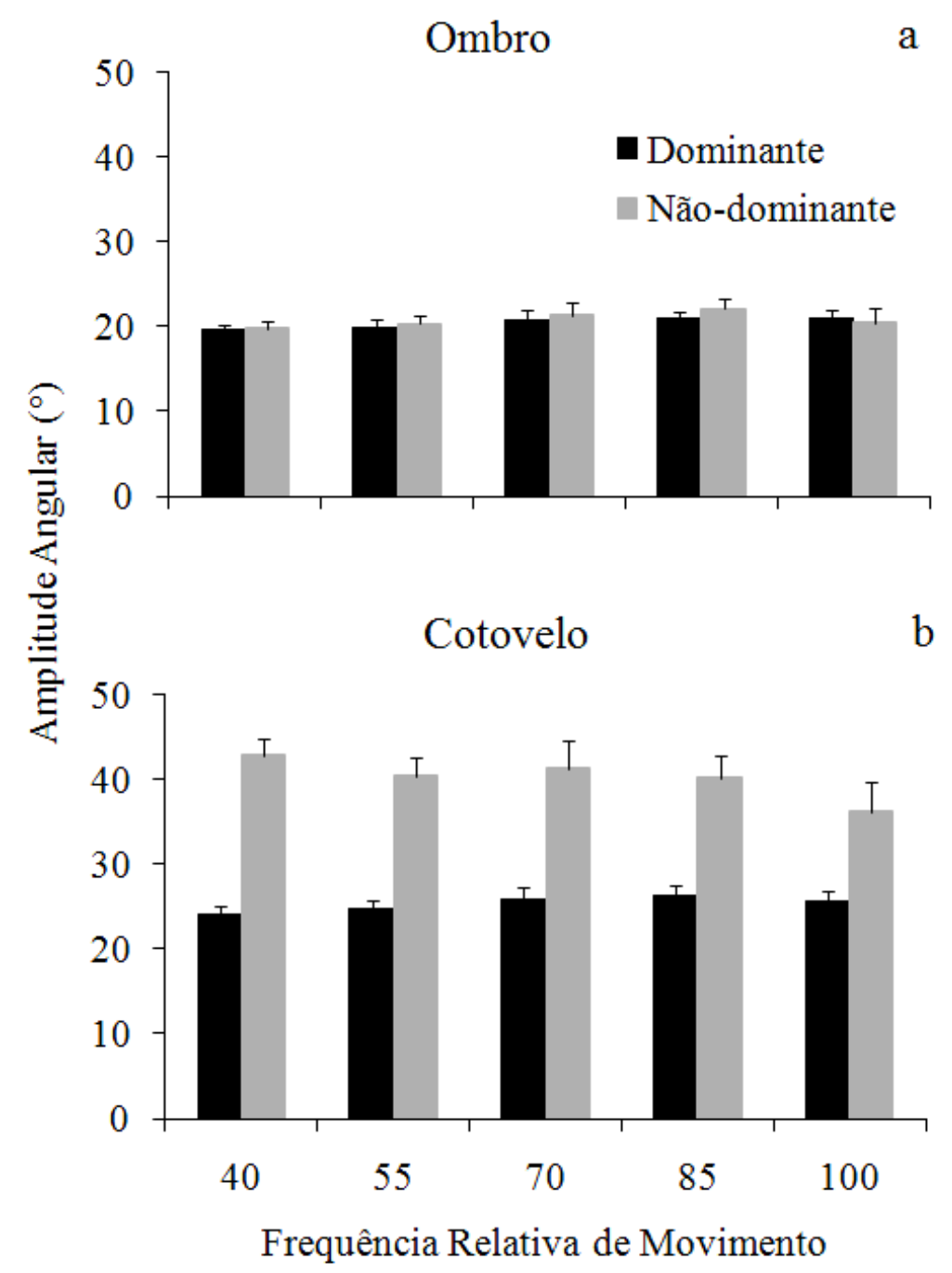

FIGURA 11 - Médias e erros-padrão (traços verticais) da amplitude angular do ombro (a) e cotovelo (b), dos braços dominante e não-dominante em função da frequência relativa de movimento. 
Variabilidade da amplitude angular do ombro

A análise da variabilidade da amplitude angular do ombro revelou efeito principal significante para os fatores braço, $F_{1,15}=32,12 ; p<0,0001$, com valores maiores para o braço não-dominante $\left(M=2,33^{\circ}\right.$; braço dominante, $\left.M=1,63^{\circ}\right)$; e frequência, $F_{4,60}=19,14 ; p<0,0001$. As comparações posteriores indicaram valores mais elevados nas três últimas frequências de movimento em comparação com as duas primeiras frequências. Foi detectada também interação significante, $F_{4,60}=2,80 ; p<0,05$. As comparações posteriores indicaram que $o$ efeito foi devido a valores maiores do braço não-dominante nas duas últimas frequências de movimento em comparação ao braço dominante, mas não nas demais frequências. Além disso, o braço não-dominante atingiu valores significantemente mais elevados nas três últimas frequências de movimento em comparação com as duas primeiras frequências (FIGURA 12, painel a).

Variabilidade da amplitude angular do cotovelo

A análise da variabilidade da amplitude angular do cotovelo apontou efeito principal significante para os fatores braço, $F_{1,15}=71,03 ; p<0,0001$, devido a valores maiores para o braço não-dominante $\left(M=4,67^{\circ}\right.$; braço dominante, $M=$ $1,70^{\circ}$ ); e frequência, $F_{4,60}=6,20 ; p<0,0001$. O efeito de frequência foi devido a valores mais altos na última frequência de movimento em comparação com as duas primeiras frequências de movimento. Foi detectada também interação significante, $F_{4,60}=3,18 ; p<0,01$. As comparações posteriores revelaram valores elevados do braço não-dominante nas três últimas frequências de movimento em comparação com a primeira frequência, e valores mais elevados na terceira e 
quinta frequência de movimento em comparação com a segunda frequência de movimento (Figura 12, painel b).

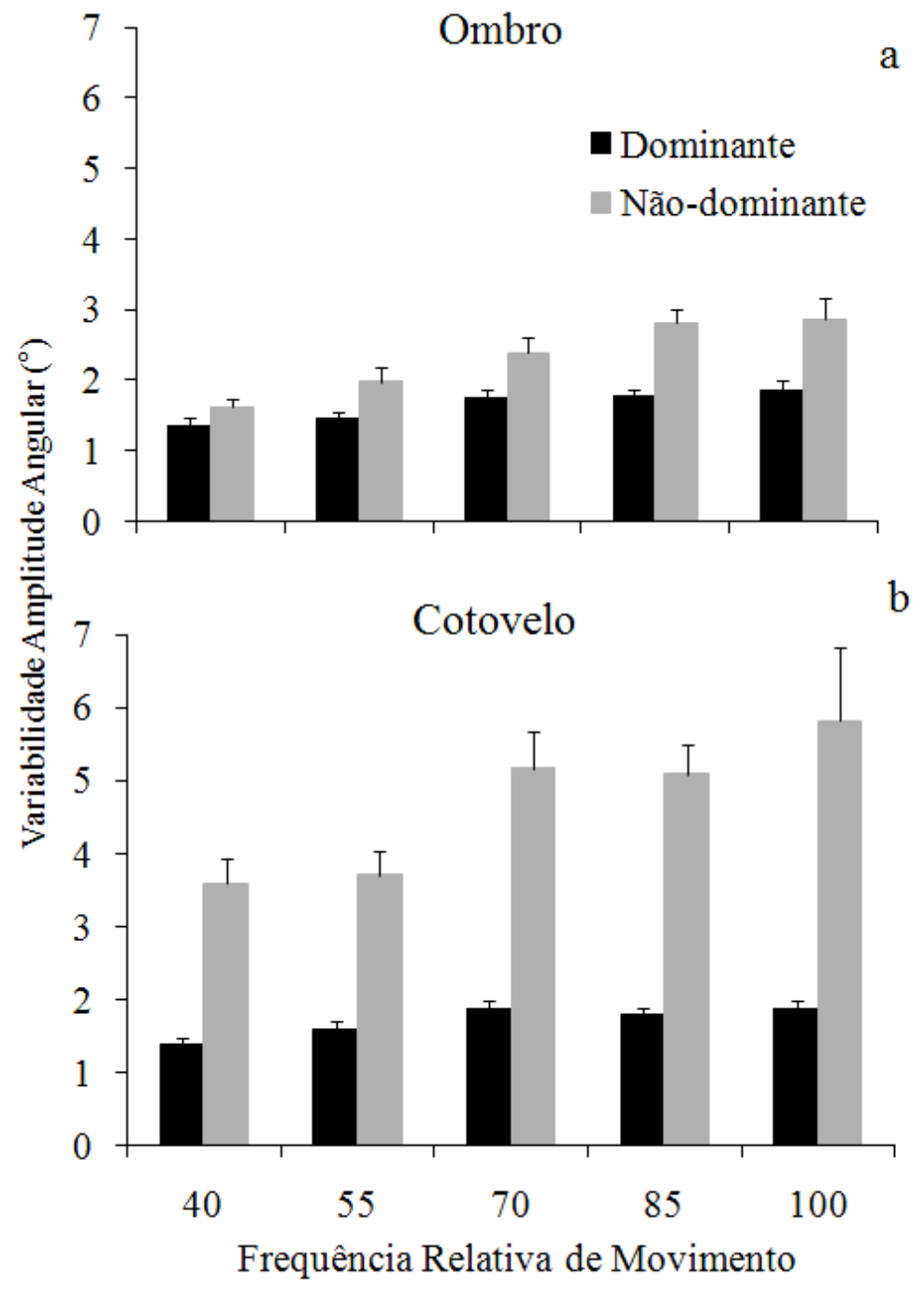

FIGURA 12 - Médias e erros-padrão (traços verticais) da variabilidade da amplitude angular do ombro (a) e cotovelo (b), dos braços dominante e não-dominante em função da frequência relativa de $\underline{\text { movimento. }}$ 
Coeficiente de amplitude ângulo-ângulo

A Figura 13 representa o comportamento médio e variabilidade da relação espacial entre as medidas angulares do ombro e do cotovelo de um participante durante a realização de movimentos realizados com o braço dominante e com o braço não-dominante em diferentes frequências de movimento.

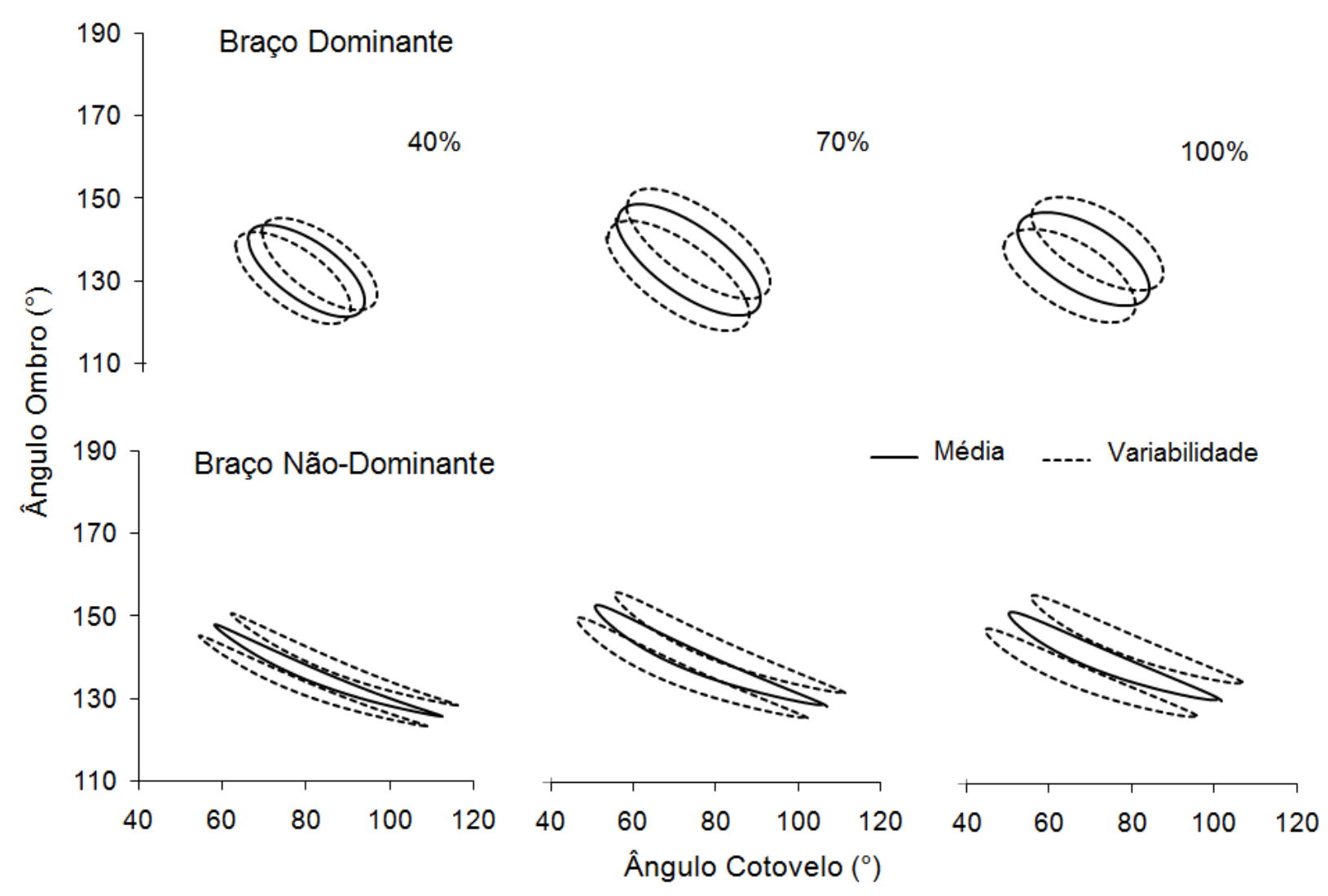

FIGURA 13 - Média (linha contínua) e variabilidade (linhas tracejadas) da relação espacial entre as medidas angulares do ombro e cotovelo em movimentos realizados com o braço dominante e braço nãodominante em diferentes frequências de movimento.

Os resultados da análise do coeficiente de amplitude angular entre o ombro e o cotovelo apresentaram efeitos principais significantes nos fatores 
braço, $F_{1,15}=94,80 ; p<0,0001$, resultante em valores mais elevados para o braço dominante $(M=0.80$; braço não-dominante, $M=0.52)$; e frequência, $F_{4,60}=$ 4,$14 ; p<0,01$. Comparações posteriores indicaram valores maiores para as duas últimas frequências de movimento em comparação com a primeira frequência. Também foi encontrada interação significante, $F_{4,60}=5,62 ; p>0,001$. Comparações posteriores indicaram que o braço não-dominante apresentou valores maiores nas três últimas frequências de movimento comparado com a primeira frequência (FIGURA 14).

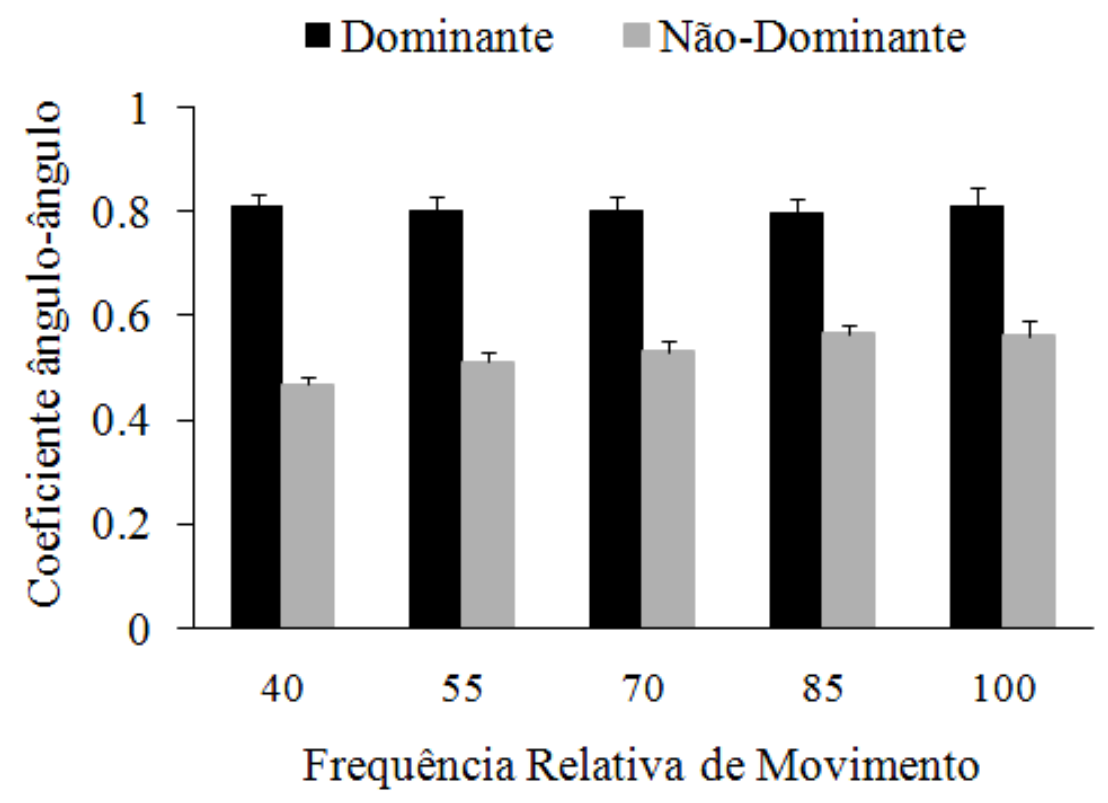

FIGURA 14 - Médias e erros-padrão (traços verticais) do coeficiente de amplitude ângulo-ângulo dos braços dominante e não-dominante em função da frequência relativa de movimento.

Variabilidade da relação ângulo-ângulo

A análise da variabilidade do coeficiente ângulo-ângulo indicou efeito principal significante para os fatores braço, $F_{1,15}=31,56 ; p<0,0001$, em função da menor variabilidade do braço dominante $\left(M=3.37^{\circ}\right.$; braço não-dominante, $M$ 
$\left.=4.40^{\circ}\right)$; e frequência, $F_{4,60}=12,48 ; p<0,0001$. Comparações posteriores revelaram menor variabilidade na frequência mais baixa em comparação com as três frequências mais altas de movimento. Não foi encontrada interação significante, $F_{4,60}=2,42$ (FIGURA 15).

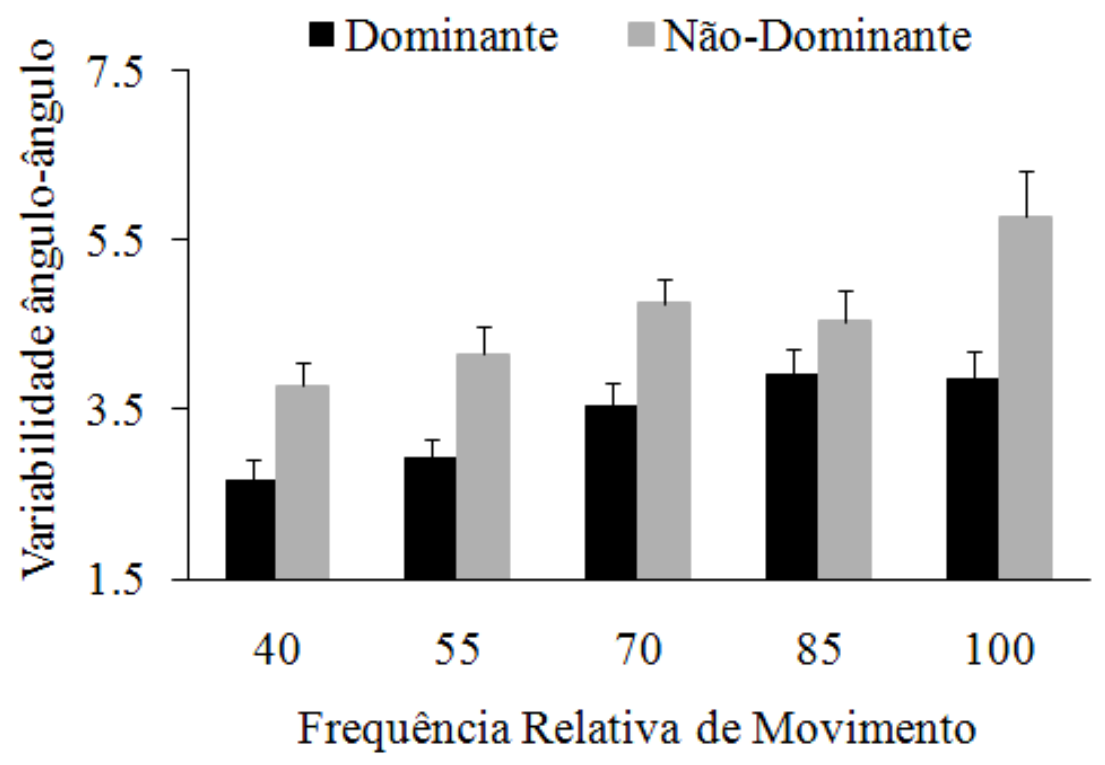

FIGURA 15 - Médias e erros-padrão (traços verticais) da variabilidade do coeficiente ângulo-ângulo do braço dominante e do braço nãodominante em função da frequência relativa de movimento.

Fase relativa (FR)

A Figura 16 representa a relação temporal do deslocamento angular do ombro e do cotovelo em uma tentativa realizada em $70 \%$ da frequência máxima. Com esta representação gráfica podemos observar o atraso do pico de flexão do cotovelo em relação ao pico de adução do ombro do braço dominante (a) e do braço não-dominante (b). 


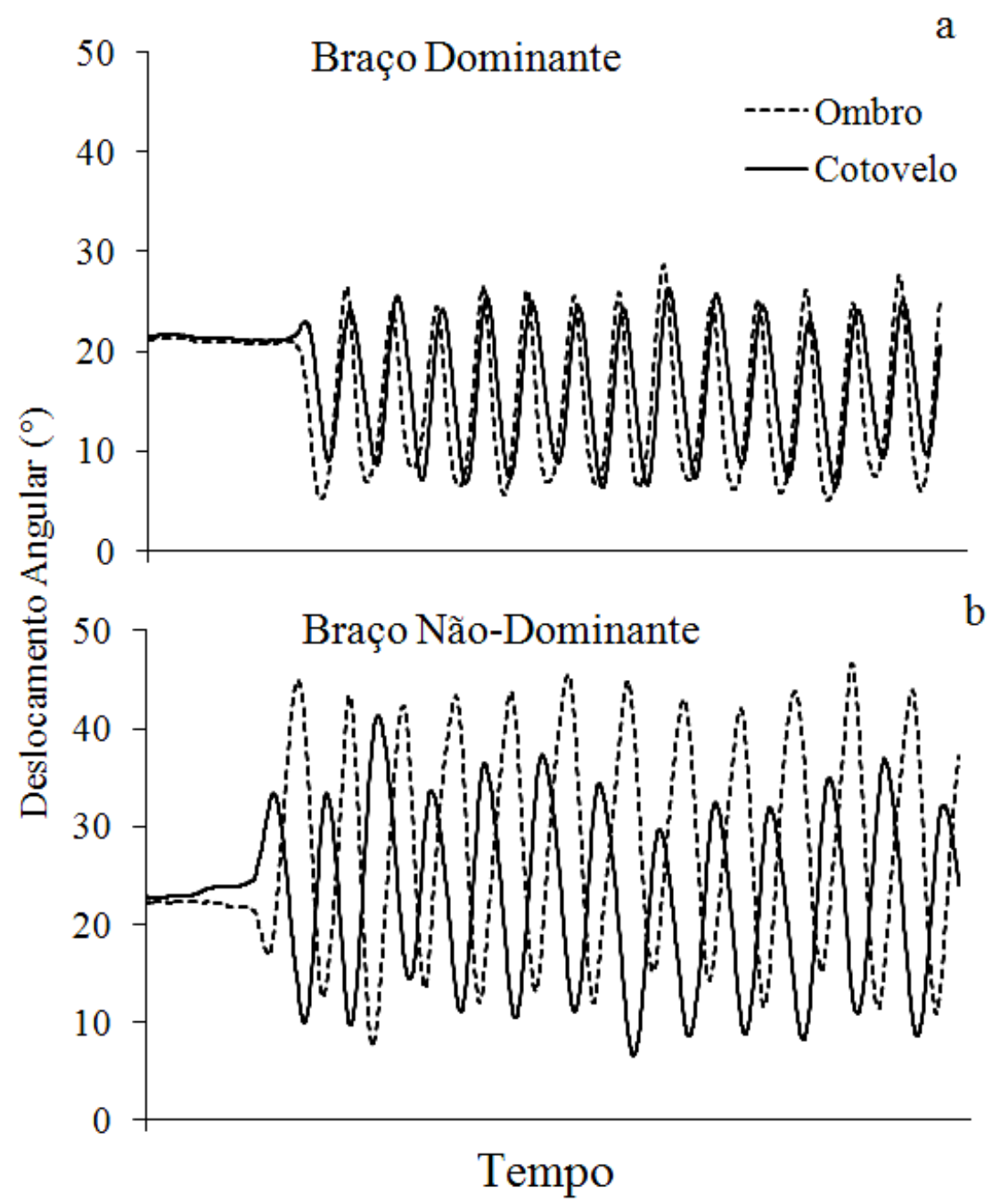

FIGURA 16 - Representação da relação temporal do deslocamento angular do ombro e do cotovelo durante movimentos circulares cíclicos do braço dominante (a) e não-dominante (b) realizado em $70 \%$ da frequência máxima.

A análise da fase relativa indicou efeito principal significante para os fatores braço, $F_{1,15}=523,21 ; p<0,0001$, decorrente de menores valores do braço dominante $\left(M=123,8^{\circ}\right.$; braço não-dominante, $\left.M=180,2^{\circ}\right)$; e frequência, $F_{4,60}=$ 5,$269 ; p<0,001$. Comparações posteriores indicaram valores menores na última frequência em comparação com as três primeiras frequências de movimento (última frequência, $M=146,5^{\circ}$; primeira frequência, $M=155,1^{\circ}$ ). A análise 
apontou interação significante, $F_{4,60}=13,76 ; p<0,0001$. Comparações posteriores indicaram que o braço não-dominante apresentou valor menor na última frequência em comparação com as demais frequências de movimento, enquanto que nenhuma diferença foi detectada entre frequências para o braço dominante (FIGURA 17).

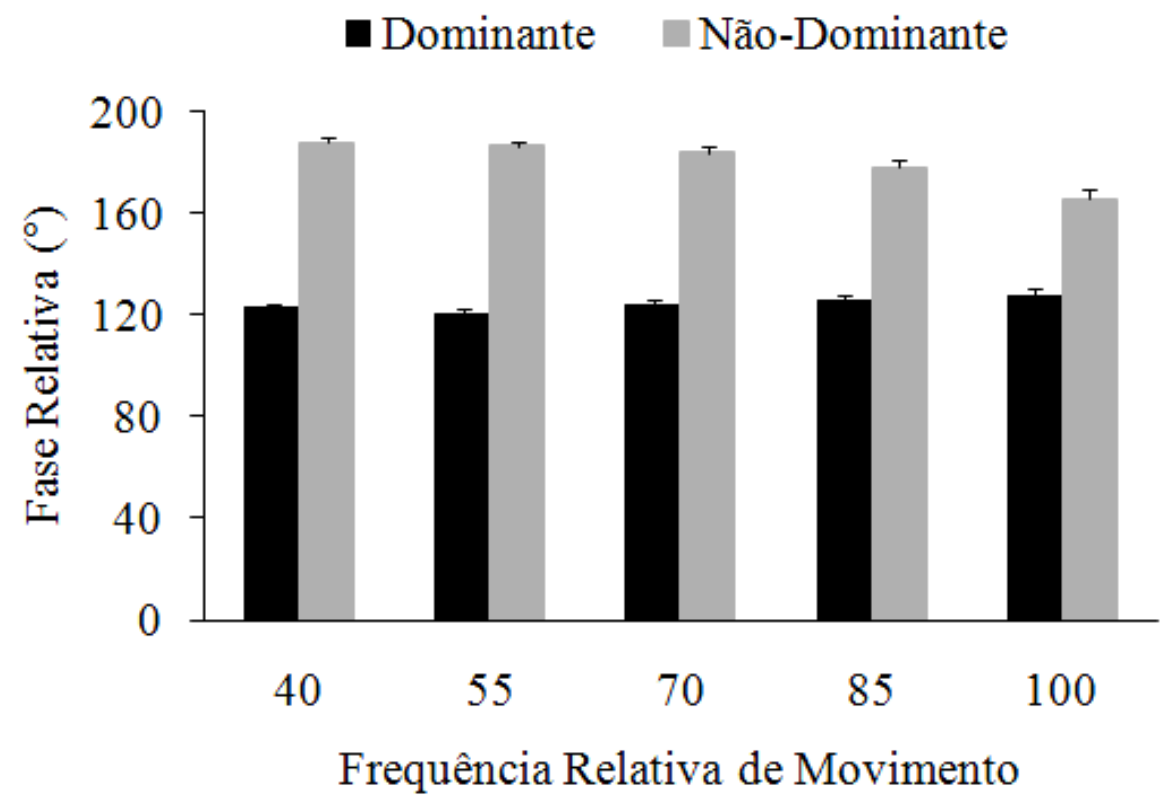

FIGURA 17 - Médias e erros-padrão (traços verticais) da fase relativa do braço dominante e não-dominante em função da frequência relativa de movimento.

Variabilidade da fase relativa

A análise de variabilidade da fase relativa indicou efeito principal significante para o fator braço, $F_{1,15}=18,18 ; p<0,001$, devido à menor variabilidade para o braço dominante $\left(M=5.54^{\circ}\right.$; braço não-dominante, $M=$ $6.72^{\circ}$ ), e para o fator frequência, $F_{4,60}=3,73 ; p<0,01$. Comparações posteriores indicaram valores menores para a segunda frequência em comparação com a 
última frequência de movimento. Não foi encontrada interação significante, $F_{4,60}$ $=0,66($ FIGURA 18).

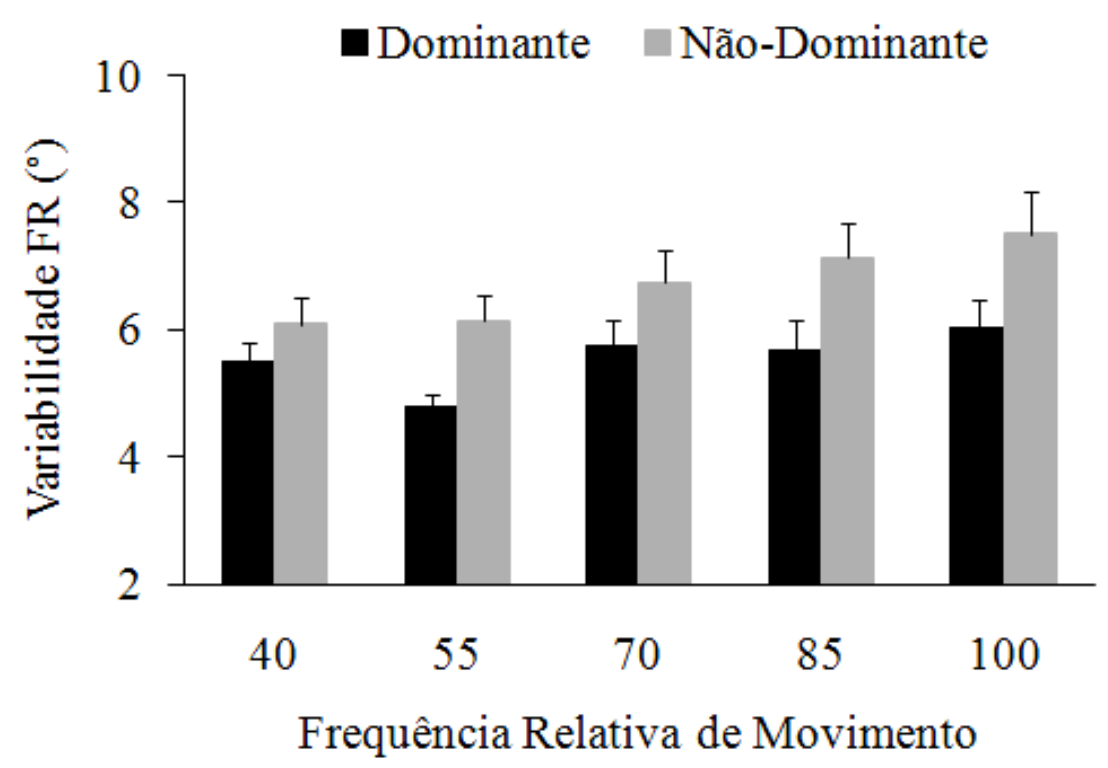

FIGURA 18 - Médias e erros-padrão (traços verticais) da variabilidade da fase relativa (FR) do braço dominante e do braço não-dominante em função da frequência relativa de movimento.

\section{DISCUSSÃO}

Este estudo teve como objetivo avaliar assimetrias intermanuais em movimentos circulares cíclicos. A avaliação foi feita em movimentos efetuados em diferentes frequências, atingindo a velocidade máxima de movimentos com o braço não-dominante. Foram avaliados tanto aspectos métricos quanto de coordenação interarticular. Foi hipotetizado que, com o aumento da frequência relativa de movimento o braço não-dominante apresentaria redução da circularidade de movimento, aumento da variabilidade da circularidade de movimento e, aumento da variabilidade da fase relativa entre as articulações do 
ombro e do cotovelo. Os resultados demonstraram que o desempenho com o braço não-dominante apresentou as seguintes diferenças em comparação com o braço dominante: perda da circularidade do movimento, trajetória da mão e amplitudes angulares mais variáveis, maior participação do cotovelo, coordenação em modo antifase (braço dominante: relação de fase de aproximadamente $120^{\circ}$ ) e maior variabilidade de modo de coordenação. De forma geral, as assimetrias interlaterais foram acentuadas em frequências de movimento mais altas. Estes resultados indicam que a vantagem de desempenho com o braço dominante é devida a um modo de coordenação mais consistente e efetivo em realizar a trajetória desejada.

\subsection{Assimetrias interlaterais de desempenho motor}

No presente estudo, os resultados demonstraram que em altas frequências de movimento o braço não-dominante apresentou perda de circularidade e maior variabilidade da circularidade do movimento em comparação ao braço dominante. Estes resultados confirmam achados prévios (CARSON et al.,1997; CATTAERT et al., 1999; TSENH \& SCHOLZ, 2005), indicando que movimentos circulares cíclicos unimanuais apresentam assimetria intermanual com vantagem observada a favor do braço dominante.

Desempenho superior com o braço dominante em relação ao braço nãodominante em tarefas de toques sequenciais em uma superfície (PETERS, 1980, 1981), em tarefas de toques discretos em um alvo (ROY \& ELLIOT, 1986, 1989; ROY et al., 1994) e em tarefas de desenhar círculos em diferentes frequências de movimento (CATTAERT et al., 1999; VERSCHUEREN et al., 1999; FRANZ et al., 2002; SPENCER et al., 2005; TSENG \& SCHOLZ, 2005) tem sido consistentemente encontrado em estudos relacionados à assimetria lateral de 
desempenho. PETERS (1980) demonstrou que em tarefas de toques sequenciais em uma superfície, o desempenho com o braço dominante é consistentemente superior, não apenas em termos de frequência (mais rápido), mas também mais consistentes quando comparado ao braço não-dominante, mesmo após um período extensivo de treinamento (PETERS, 1981). Adicionalmente, ROY e ELLIOT $(1986,1989)$ demonstraram que os movimentos feitos com o braço dominante são mais rápidos e mais precisos do que aqueles realizados com o braço não-dominante em tarefa de toques discretos em um alvo. Baseados nos resultados apresentados em estudos prévios (ANNET et al., 1979; PETERS, 1980, 1981; ROY \& ELLIOT, 1986, 1989; ROY et al., 1994;), a maior variabilidade da circularidade apresentada no presente estudo com o braço nãodominante em altas velocidades de movimento sugere que o sistema neuromotor não-dominante apresenta menor capacidade de lidar com as forças musculares geradas no movimento, gerando instabilidade no ato motor (PETERS, 1980, 1981; ANNET et al., 1979; SAINBURG, 2002). Estes resultados (PETERS, 1980, 1981; ROY \& ELLIOT, 1986, 1989) correspondem à evidência de que existem assimetrias na constituição dos dois hemisférios cerebrais, tornando um dos lados do corpo mais apto a desempenhar determinadas funções sensoriomotoras do que o lado contrário. Uma dessas funções corresponde a contrações rápidas e alternadas de determinados músculos da mão ou do braço, gerando movimentos oscilatórios de alta frequência de toques sequenciais em uma superfície (PETERS, 1980, 1981) ou movimentos circulares cíclicos, como no presente estudo. Outra função consiste na realização de movimentos envolvendo velocidade e precisão em movimentos orientados a um alvo espacial, como evidenciado nos estudos de FLOWERS (1975), ROY \& ELLIOT, (1986, 1989), SAINBURG (2002), BAGESTEIRO \& SAINBURG (2005), SCHAEFER et al. (2007). Portanto, estes resultados correspondem à evidência de que estas 
assimetrias estão relacionadas à modulação superior da força no controle do braço dominante.

Resultados complementares relacionados à assimetria manual de desempenho demonstraram no presente estudo que a frequência de movimento do braço dominante tendeu a ser adiantada em relação à frequência do metrônomo comparada ao braço não-dominante. Tal adiantamento ocorreu principalmente nas frequências mais baixas de movimento. Tais resultados estão em consonância com os achados do estudo de CARSON et al. (1997), em que os participantes (destros) realizavam movimentos circulares cíclicos, em frequência inicial do metrônomo de $1,5 \mathrm{~Hz}$ até uma frequência de $3 \mathrm{~Hz}$, com degraus de $0,25 \mathrm{~Hz}$. Os resultados demonstraram que a frequência de movimento do braço dominante tendeu a ser adiantada em relação à frequência do metrônomo em todas as condições. A partir dessas evidências fica aparente que a frequência de movimento preferida do braço dominante é maior comparada a do braço nãodominante.

8.2 Efeito da frequência de movimentos sobre as assimetrias interlaterais na coordenação interarticular.

Assimetrias interlaterais na coordenação interarticular que levam a maior variabilidade espacial ou à perda de circularidade de movimentos encontrada em altas velocidades de movimento com o braço não-dominante correspondem a um achado original do presente estudo. Estudos prévios que utilizaram ações manuais circulares cíclicas como tarefa para analisar a assimetria na coordenação de movimentos manuais em diferentes frequências de movimentos têm se concentrado principalmente na análise das estratégias de controle motor intermembros (e.g., KELSO, 1984; SEMJEN et al. 1995; SUMMERS et al. 
1995; CARSON et al. 1997; CATTAERT et al. 1999) ou analisaram de forma limitada a coordenação interarticular (e.g., TSENG \& SCHOLZ, 2005), não oferecendo dados mais refinados sobre as variações do modo de coordenação interarticular.

No presente estudo, foram detectados distintos modos de coordenação interarticular entre os dois braços, definidos em função da relação temporal e da relação espacial entre os movimentos do ombro e do cotovelo. Os resultados mostraram que o modo de coordenação temporal adotado pelo braço dominante, em um modo de coordenação fora-de-fase, foi mantido ao longo de todas as frequências de movimentos testadas, com reduzida variabilidade dos valores de fase relativa. $\mathrm{O}$ modo de coordenação adotado pelo braço não-dominante, no modo antifase, foi mantido com relativa estabilidade nas frequências mais baixas. Entretanto, quando a frequência de movimento atingiu a frequência máxima, houve uma diminuição da fase relativa entre os movimentos das duas articulações, indicando um modo de coordenação diferente daquele adotado nas frequências mais baixas de movimento. Houve também aumento significante da variabilidade da fase relativa com o aumento da frequência de movimento. Em termos espaciais, alguns marcos importantes da relação espacial de amplitude angular do ombro e do cotovelo confirmam estas diferenças no padrão de coordenação entre os braços. O braço não-dominante apresentou uma relação inversa quase perfeita entre abdução de ombro e flexão de cotovelo e uma variabilidade ângulo-ângulo crescente conforme a frequência de movimentos foi aumentada. Em contrapartida, o braço dominante, por sua vez, não apresentou uma relação espacial direta entre abdução de ombro e flexão de cotovelo, mas sim uma dissociação dessa relação espacial, e uma baixa variabilidade ânguloângulo ao longo de todas as frequências de movimento avaliadas. Esses resultados permitem extrair algumas conclusões importantes. $\mathrm{O}$ primeiro aspecto 
a ser observado nesses resultados é que os braços adotam diferentes modos de coordenação interarticular para realizar a trajetória do movimento de forma circular. O segundo aspecto importante a ser observado é que a diminuição da fase relativa e o aumento da variabilidade com o braço não-dominante em altas frequências de movimento resultou na maior variabilidade da circularidade do movimento comparado ao braço dominante. Um aspecto adicional a ser considerado é que a mudança da relação temporal antifase para o modo fora-defase com o braço não-dominante em frequências mais altas de movimento mostra que modos de coordenação estáveis em uma frequência baixa de movimentos podem ser desestabilizados com aumento da frequência, levando o sistema a mudar para um modo mais estável do que aquele originalmente adotado (KELSO, 1984; SCHOLZ \& KELSO, 1990). Isso significa que, com o braço dominante, a ação foi executada de forma estável, com baixa variabilidade das características do movimento, com preservação do padrão de coordenação em altas velocidades de movimento em comparação com o braço não-dominante. Outra característica importante associada ao modo eficiente de coordenação interarticular é a capacidade superior do membro dominante em lidar com a dinâmica do movimento, ou seja, lidar com as forças geradas em cada articulação envolvida no movimento de forma eficiente (DOUNSKAIA et al., 2002; SAINBURG, 2005). Os resultados obtidos no presente estudo estão em consonância com achados de uma série de estudos experimentais utilizando tarefas discretas, com indivíduos destros, os quais têm revelado uma vantagem favorável ao braço dominante devido ao melhor controle dinâmico da coordenação intersegmentar, levando a movimentos mais retilíneos em ações de alcançar um alvo, por exemplo, comparado ao braço não-dominante (e.g., SAINBURG \& KALAKANIS, 2000; SAINBURG, 2002; BAGESTEIRO \& SAINBURG, 2002; SAINBURG \& WANG, 2002; WANG \& SAINBURG, 
2003; WANG \& SAINBURG, 2007; SCHAEFER et al., 2007; SHABBOTT \& SAINBURG, 2008).

Uma proposição que tem sido usada para explicar a assimetria de desempenho entre os braços em tarefas de pontaria e pode ser generalizada para movimentos circulares cíclicos é a hipótese da dominância dinâmica de Sainburg (2002). Esta hipótese propõe que o sistema hemisfério cerebral esquerdo/braço direito em indivíduos destros é especializado no controle da dinâmica da trajetória do membro, enquanto que o hemisfério contralateral é especializado no controle da posição final do membro, em tarefa de movimentos de alcançar um alvo no espaço (BAGESTEIRO \& SAINBURG, 2002, 2003; SAINBURG, 2002; SAINBURG \& WANG, 2002; WANG \& SAINBURG, 2007). Além disso, de acordo com essa proposição, a especialização do braço dominante no controle da trajetória do membro está relacionada ao mecanismo de controle feedforward, enquanto que o movimento do braço não-dominante se distinguiria principalmente pelo uso de mecanismos de feedback no posicionamento final da mão sobre o alvo espacial (BAGESTEIRO \& SAINBURG, 2002, 2003; SAINBURG, 2005). Considerando que em movimentos circulares cíclicos o componente principal é a trajetória da mão de execução e que os resultados do presente estudo revelaram um modo de coordenação interarticular mais estável e eficiente para o braço dominante principalmente em altas velocidades de movimento em comparação ao braço não-dominante, podemos inferir que a hipótese da dominância dinâmica se aplica a ações manuais circulares cíclicas.

Algumas considerações serão feitas com relação ao que foi abordado no parágrafo anterior. Em concordância com a hipótese da dominância dinâmica (SAINBURG, 2002), é possível supor que os resultados do presente estudo relacionados à maior estabilidade do modo de coordenação entre as articulações do ombro e do cotovelo do braço dominante em comparação ao braço não- 
dominante seria devido a sua superioridade no controle da dinâmica intersegmentar. Em outros termos, o braço dominante apresenta maior capacidade em lidar com as forças musculares geradas para produzir o movimento e, em lidar com a interação dessas forças com as forças inerciais agindo sobre o braço do executante (SAINBURG \& KALAKANIS, 2000; SAINBURG, 2002). Além disso, em altas velocidades de movimento, em que a execução da tarefa é baseada mais em pré-programação motora e menos em uso de feedback (DONKELAAR \& FRANKS, 1991), esta maior estabilidade no modo de coordenação do braço dominante se torna mais evidente pelo fato de que, o controle da trajetória do membro e da dinâmica da tarefa está especificamente relacionada ao mecanismo de controle feedforward (BAGESTEIRO \& SAINBURG, 2002, 2003; SAINBURG, 2005). Por outro lado, a maior variabilidade da relação temporal e espacial interarticular encontrada em altas velocidades de movimento com o braço não-dominante seria decorrente da menor capacidade de lidar com a interação das forças musculares e forças inerciais agindo sobre o braço. Como também ao pouco tempo disponível para a utilização apropriada dos processos de regulação de movimento via feedback (BAGESTEIRO \& SAINBURG, 2003). Uma vez que, não há tempo suficiente para a interpretação dos sinais aferentes e para que os comandos motores sejam enviados ao sistema muscular a tempo para que ocorram os ajustes necessários. Contudo, os resultados do presente estudo suportam a hipótese de dominância dinâmica (SAINBURG, 2002), indicando que assimetrias interlaterais de desempenho na coordenação das articulações do ombro e cotovelo em ações manuais circulares cíclicas surgem devido a uma capacidade superior do membro dominante em lidar com a dinâmica do movimento. 
Outra importante evidência, de particular interesse neste estudo, são as assimetrias interlaterais das estratégias de controle das amplitudes angulares do ombro e do cotovelo durante a realização da tarefa. Os resultados do presente estudo revelaram que as amplitudes angulares do ombro foram semelhantes entre os braços e não foram afetadas pela manipulação da velocidade. No entanto, assimetria interlateral de desempenho foi observada com relação às amplitudes angulares do cotovelo. O braço não-dominante apresentou maior amplitude angular em comparação ao braço dominante e, variabilidade crescente conforme aumentava a velocidade de movimento, enquanto que nenhuma diferença entre frequências foi detectada para o braço dominante. Estes resultados demonstraram diferentes funções das duas articulações na realização do movimento, levando a assimetrias interlaterais de desempenho (DOUNSKAIA, 2005). Em um estudo realizado por DOUNSKAIA et al. (2002), diferentes formas de desenho, como círculo e elipse em diferentes direções, foram manipuladas para estudar as características do modo de controle das articulações do ombro e do cotovelo do braço dominante durante movimentos cíclicos. Os resultados demonstraram diferentes funções das duas articulações na realização do movimento. O controle do ombro foi similar em todas as direções de movimento, criando uma base para todo o movimento do braço. Foi observado que a variabilidade na trajetória final do movimento foi dada pelas diferenças no controle do cotovelo, servindo como um sintonizador fino da trajetória final do movimento (DOUNSKAIA et al., 1998, 2000, 2002). Com base nessas evidências, os dados de amplitudes angulares do presente estudo permitem propor que a maior variabilidade da circularidade e perda de circularidade do movimento encontrada com o braço não-dominante em altas velocidades é atribuída pelas diferenças de controle da articulação do cotovelo, uma vez que, o controle da articulação do ombro não diferiu entre os braços. Essa diferença de controle considera que o controle da 
articulação do ombro de ambos os braços atuem como uma base para todo o movimento, enquanto o controle da articulação do cotovelo ajusta a trajetória final do movimento para as exigências da tarefa (DOUNSKAIA et al., 2000, 1998, 2002; VERSCHUEREN et al., 1999). Quando há um aumento da velocidade de movimento a articulação do cotovelo do braço não-dominante torna-se menos eficiente nos ajustes do movimento devida à limitação no tempo disponível para utilização apropriada dos processos de regulação de movimento via feedback (BAGESTEIRO \& SAINBURG, 2003; DOUNSKAIA et al., 1998; VERSCHUEREN et al., 1999), resultando dessa forma, em uma maior variabilidade de amplitude angular do cotovelo em comparação ao braço dominante.

Estas assimetrias interlaterais no controle das amplitudes angulares do ombro e do cotovelo durante os movimentos circulares cíclicos podem estar relacionadas ao controle descendente dos circuitos medulares. As funções dos diferentes neurônios motores superiores são estabelecidas em função da maneira pela qual os neurônios motores inferiores e neurônios de circuitos locais estão arranjados na medula espinhal (PURVES, AUGUSTINE, FITZPATRICK, KATZ, LAMANTIA, McNAMARA, WILLIANS, 2005, p. 370). A porção mais medial do corno ventral contém conjuntos de neurônios motores inferiores que inervam músculos proximais dos membros, enquanto as porções mais laterais contêm neurônios motores inferiores que inervam os músculos distais dos membros. Os neurônios de circuito local, localizados basicamente na zona intermediária da medula, apresentam padrões de conexão da região medial da zona intermediária diferentes daqueles da região lateral, e tais diferenças relacionam-se com suas respectivas funções. Os neurônios mediais de circuito local que suprem os neurônios motores inferiores do corno ventral medial possuem axônios que se estendem a vários segmentos da medula e terminam 
bilateralmente. Esse arranjo garante que grupos de músculos proximais de ambos os lados do corpo atuem em conjunto para manter e ajustar a postura. Em contraste, neurônios de circuito local que suprem as porções laterais do corno ventral possuem axônios que se estendem a poucos segmentos medulares e são predominantemente ipsilaterais. Esse padrão mais restrito de conectividade embasa o controle mais fino e diferenciado feito sobre os músculos distais, como aquele necessário para ajustar a trajetória final do movimento durante tarefas manuais (PURVES et al., 2005). Contudo, as diferentes funções da articulação do ombro e do cotovelo na realização do movimento estão em conformidade com essas diferenças funcionais entre os circuitos locais, que organizam a atividade dos grupos musculares proximais (articulação do ombro) e distais (articulação do cotovelo).

8.3 Relação entre variabilidade e velocidade de movimento.

A proposição feita por ANNETT et al. (1979), com base no modelo de variabilidade do impulso de SCHMIDT et al. (1978), de que o sistema neuromotor dominante consegue lidar de forma mais precisa com as forças geradas no movimento, apontam para uma menor variabilidade de movimento com o braço dominante em altas velocidades de movimento. De acordo com esta proposição, neste estudo a expectativa era de encontrar nas variáveis indicadoras da estabilidade do movimento vantagem de desempenho motor com o braço dominante nas frequências mais altas de movimento. Os resultados das variáveis indicadoras da estabilidade do movimento (variabilidade da circularidade, variabilidade da amplitude angular, variabilidade da relação ângulo-ângulo) confirmam a hipótese do presente estudo, indicando um aumento crescente da variabilidade de movimento com o braço não-dominante conforme aumentava a 
velocidade de movimento em comparação ao braço dominante. Resultados análogos foram encontrados em estudos prévios (CARSON et al., 1997; CATTAERT et al., 1999; TSENG \& SCHOLZ, 2005), indicando que os movimento com o braço não-dominante são mais variáveis com o aumento da frequência de movimento em comparação ao braço dominante.

O aumento da variabilidade de movimento obtido com a elevação da velocidade de movimento tem sido explicado pela concepção de que a variabilidade na produção de forças musculares acompanha a magnitude da força aplicada (SCHMIDT et al., 1979). Como forças musculares são as responsáveis pela geração de movimento, sua variação conduz também à variabilidade das características espaciais da ação. Nesse contexto, a geração de forças musculares diferentes daquelas desejadas pelo indivíduo é interpretada como sendo resultante de um ruído neural na geração dos sinais eferentes para o sistema muscular. A partir de tal conjectura, os dados do presente estudo permitem inferir que a maior variabilidade de movimentos efetuados com o braço nãodominante em altas velocidades seria originária da menor capacidade do sistema neuromotor não-dominante em lidar com as forças geradas no movimento (ANNETT et al., 1979; SAINBURG, 2002). Além disso, movimentos erráticos necessitam de maior número de correções, e a maior variabilidade de movimento exigiria mais tempo para que os ajustes fossem efetuados (BAGESTEIRO \& SAINBURG, 2003). Por outro lado, a menor variabilidade de movimentos apresentada com o braço dominante em altas velocidades de movimento seria devido a capacidade de o sistema neuromotor dominante lidar de forma mais precisa com as forças geradas no movimento (ANNETT et al., 1979; SAINBURG, 2002) e, por estar especificamente relacionado ao mecanismo de controle feedforward (BAGESTEIRO \& SAINBURG, 2003), uma vez que, em altas velocidades de movimento a execução da tarefa é baseada mais em pré- 
programação motora e menos em uso de feedback (DONKELAAR \& FRANKS, 1991).

\section{CONCLUSÕES}

Os resultados aqui apresentados indicaram originalmente diferenças entre a coordenação dos braços dominante e não-dominante, a saber: (1) os movimentos do braço dominante e não-dominante são coordenados com relações de fase diferentes, (2) o modo de coordenação do braço dominante é mais estável do que aquele do braço não-dominante nas diferentes frequências de movimento e (3) aumento crescente da variabilidade de movimento com o braço nãodominante conforme aumenta a velocidade de movimento em comparação ao braço dominante. Tais diferenças podem subjazer diferenças fundamentais no controle entre os membros dominante e não-dominante.

\section{SUGESTÕES PARA ESTUDOS FUTUROS}

Como movimentos circulares estão relacionados a desenhos, que são praticados predominantemente com o braço dominante, as assimetrias aqui encontradas poderiam ser derivadas de prática. Para abordar esta questão, sugerese que o presente estudo seja replicado em crianças em tenra idade. Dessa forma, poderia ser avaliada a extensão em que as assimetrias intermanuais aqui encontradas se manifestam precocemente durante o ciclo de desenvolvimento humano ou somente após várias experiências unimanuais em tarefas gráficas. 


\section{REFERÊNCIAS}

ANNETT, J., ANNETT, M., \& HUDSON, P.T.W. The control of movement in the preferred and non-preferred hands. The Quarterly Journal of Experimental Psychology, v.31, p.641-52, 1979.

BAGESTEIRO, L.B., \& SAINBURG, R.L. Handedness: dominant arm advantages in control of limb dynamics. Journal of Neurophysiology, v.88, p.2408-21, 2002.

BAGESTEIRO, L.B., \& SAINBURG, R.L. Non-dominant advantages in load compensation during rapid elbow joint movements. Journal of Neurophysiology, v.90, p.1503-13, 2003.

BAGESTEIRO, L.B., \& SAINBURG, R.L. Interlimb transfer of load compensation during rapid elbow joint movements. Experimental Brain Research, v.161, n.2, p.155-65, 2005.

BRYDEN, M.P. Choosing sides: the left and right of the normal brain. Canadian Psychology, v.31, n.4, p.297-309, 1990.

BYBLOW, W.D., SUMMERS, J. J., SEMJEN, A., WUYTS, I. J., CARSON, R. G. Spontaneous and intentional pattern switching in a multisegmental bimanual coordination task. Motor Control, v.3, p.372-393, 1999.

CARSON, R.G., CHUA, R., ELlIOTT, D., \& GOODMAN, D. Asymmetries in the discrete and pseudocontinuous regulation of visually guided reaching. Brain and Cognition, v.18, p.169-91, 1992. 
CARSON, R., THOMAS, J., SUMMERS, J.J., WALTERS, M.R., SEMJEN, A. The dynamics of bimanual circle drawing. The Quarterly Journal of Experimental Psychology, v.50A, p.664-83, 1997.

CATTAERT, D., SEMJEN, A., SUMMERS, J.J. Simulating a neural cross-talk model for between-hand interference during bimanual circle drawing. Biological Cybernetics, v.81, p.343-58, 1999.

DONKELAAR, P. van \& FRANKS, I.M. Preprogramming versus on-line control in simple movement sequences. Acta Psychologica, v.77, p.1-19, 1991.

DOUNSKAIA, N., SWINNEN, S. P., WALTER, C. B., SPAEPEN, A. J., VERSCHUEREN, S. M. Hierarchical control of different elbow-wrist coordination patterns. Experimental Brain Research, v.121, n.3, p.239-254, 1998.

DOUNSKAIA, N., VAN GEMMERT, A. W. A., \& STELMACH, G. E. Interjoint coordination during handwriting-like movements. Experimental Brain Research, v.135, p.127-140, 2000.

DOUNSKAIA, N., KETCHAM, C. J., STELMACH, G. E. Influence of biomechanical constraints on horizontal arm movements. Motor Control, v.6, n.4, p.366-387, 2002.

DOUNSKAIA, N. The internal model and the leading joint hypothesis: implications for control of multi-joint movements. Experimental Brain Research, v.166, p.1-16, 2005.

DOUNSKAIA, N., NOGUEIRA, K. G., SWINNEN, S. P., \& DRUMMOND, E. Limitations on Coupling of Bimanual Movements Caused by Arm Dominance: 
When the Muscle Homology Principle Fails. Journal of Neurophysiology, v.103, p.2027-38, 2010.

DUFF, S. V., SAINBURG, R. L. Lateralization of motor adaptation reveals independence in control of trajectory and steady-state position. Experimental Brain Research, v.179, p.551-561, 2007.

ELLIOTT, D., ROY, E.A., CARSON, R.G., CHUA, R., \& MARAJ, B.K.V. Asymmetries in the preparation and control of manual aiming movements. Canadian Journal of Experimental Psychology, v.47, n.3, p.570-89, 1993.

FLOWERS, K. A. Handedness and controlled movements. British Journal of Psychology, v.66, n.1, p.39-52, 1975.

FRANZ, E. A., ROWSE, A., \& BALLANTINE, B. Does handedness determine which hand leads in a bimanual task? Journal of Motor Behavior, v.34, n.4, p.402-412, 2002.

HAALAND, K.Y., HARRINGTON, D.L. Hemispheric asymmetry of movement. Current Opinion Neurobiology, v.6, p.796-800, 1996.

HAALAND, K.Y., PRESTOPNIK, J. L., KNIGHT, R. T., LEE, R. R. Hemispheric asymmetries for kinematic and positional aspects of reaching. Brain, v. 127, p.1145-58, 2004.

LACQUANITI, F., FERRIGNO, G., PEDOTTI, A., SOECHTING, J. F., TERZUOLO, C. A. Changes in spatial scale in drawing and handwriting: kinematic contributions by proximal and distal joints. Journal of Neuroscience, v.7, p.819-828, 1987. 
KELSO, J.A.S. Phase transitions and critical behavior in human bimanual coordination. American Physiological Society, v.15, p.R1000-R1004, 1984.

KELSO, J. A. S., BUCHANAN, J. J., WALLACE, S. A. Order parameters for the neural organization of single, multijoint limb movement patterns. Experimental Brain Research, v.85, p.432-444, 1991.

OLDFILD, R.C. The assessment and analysis of hand handedness: the Edimburg inventory. Neuropsychologia, v.9, p.97-113, 1971.

PETERS, M. Prolonged practice of simple motor task by preferred and nonpreferred hands. Perceptual and Motors Skills, v.43, p. 447-50, 1976.

PETERS, M. Handedness: Effect of prolonged practice on between hand performance differences. Neuropsychologia, v.19, n.4, p.587-90, 1981.

PROVINS, K.A., MILNER, A.D., \& KERR, P. Asymmetry of manual preference and performance. Perceptual and Motor Skills, v.54, p.179$194,1982$.

PURVES, D., AUGUSTINE, G. J., FITZPATRICK, D., KATZ, L. C., LAMANTIA, A. S., MCNAMARA, J. O., \& WILLIAMS, S. M. Controle motor superior do tronco encefálico e da medula espinhal. Neurociências, cap.17, p.370, 2005.

ROY, E.A., \& ELLIOTT, D. Manual asymmetries in visually directed aiming. Canadian Journal of Psychology, v.40, n.2, p.109-21, 1986.

ROY, E.A., \& ELLIOTT, D. Manual asymmetries in aimed movements. The Quarterly Journal of Experimental Psychology, v.41A, n.3, p.501-16, 1989. 
ROY, E.A., KALBFLEISH, L., \& ELLIOTT, D. Kinematic analysis of manual asymmetries in visual aiming movements. Brain and Cognition, v.24, p.289-95, 1994.

SAINBURG, R.L., GHILARDI, M.F., POIZNER, H., \& GHEZ, C. Control of limb dynamics in normal subjects and patients without proprioception. Journal of Neurophysiology, v.73, p.820-35, 1995.

SAINBURG, R.L., \& KALAKANIS, D. Differences in control of limb dynamics during dominant and non-dominant arm reaching. Journal of Neurophysiology, v.83, p.2661-75, 2000.

SAINBURG, R.L. Evidence for a dynamic-dominance hypothesis of handedness. Experimental Brain Research, v.142, p.241-58, 2002.

SAINBURG, R.L., \& WANG, J. Interlimb transfer of visuomotor rotations: independence of direction and final position information. Experimental Brain Research, v.145, n.4, p.437-47,2002.

SAINBURG, R.L., \& SCHAEFER, S.Y. Interlimb differences in control of movement extent. Journal of Neurophysiology, v.92, p.1374-1383, 2004.

SAINBURG, R. L. Handedness: Differential specializations for control of trajectory and position. Exercise and Sport Sciences Reviews, v. 33, n. 4, p. 206-213, 2005.

SCHAEFER, S.Y., HAALAND, K. Y., \& SAINBURG, R. L. Ipsilesional motor deficits following stroke reflect hemispheric specializations for movement control. Brain, v. 130, p. 2146-58, 2007. 
SCHMIDT, R.A.; ZELAZNIK, H.N.; FRANK, J.S. Sources of inaccuracy in rapid movement. In: G.E. STELMACH (Ed.), Information processing in motor control and learning. New York, Academic Press, p.183-203, 1978.

SCHMIDT, R.A.; ZELAZNIK, H.; HAWKINS, B.; FRANK, J.S.; QUINN, J.T. Motor-output variability: A theory for the accuracy of rapid motor acts. Psychological Review, v.86, n.5, p.415-451, 1979.

SCHOLZ, J. P., \& KELSO, J. A. S. A quantitative approach to understanding the formation and change of coordinated movement patterns. Journal of Motor Behavior, v. 21, n.2, p.122-144, 1989.

SCHOLZ, J. P., \& KELSO, J. A. S. Intentional switching between patterns of bimanual coordination is depend on the intrinsic dynamics of the patterns. Journal of Motor Behavior, v.22, p.98-124, 1990.

SHABBOTT, B. A., \& SAINBURG, R. L. Differentiating Between Two Models of Motor Lateralization. Journal of Neurophysiology, v.100, p.565-75, 2008.

SPENCER, R. M. C., IVRY, R. B., CATTAERT, D., \& SEMJEN, A. Bimanual Coordination During Rhythmic Movements in the Absence of Somatosensory Feedback. Journal of Neurophysiology, v.94, p.2901-10, 2005.

STERGIOU, N. Considerations of movement variability in biomechanics research. Innovative analyses of human movement, cap.2, p.54-56, 2004.

SUMMERS, J.J., SEMJEN, A., CARSON, R.G., \& THOMAS, J. Going around in circles: The dynamics of bimanual circling. In: Motor Control and Sensory Motor Integration, p.231-53, 1995. 
SEMJEN, A., SUMMERS, J. J., \& CATTAERT, D. Hand coordination in bimanual circle drawing. Journal of Experimental Psychology: Human Perception and Performance, v.21, p.1139-57, 1995.

TEIXEIRA, L.A., \& PAROLI, R. Assimetrias laterais em ações motoras: Preferência versus desempenho. Motriz, v.6, n.1, p.1-8, 2000.

TSENG, Y.W., SCHOLZ J.P. Unilateral vs. bilateral coordination of circledrawing tasks. Acta Psychologica, v.120, p.172-98, 2005.

TSENG, Y. W., SCHOLZ, J. P. Effects of Movement Frequency and Joint Kinetics on the Joint Coordination Underlying Bimanual Circle Drawing. Journal of Motor Behavior, v.38, n.5, p.383-404, 2006.

VERSCHUEREN, S. M., SWINNEN, S. P., CORDO, P. J., DOUNSKAIA, N.V. Proprioceptive control of multijoint movement: bimanual circle drawing. Experimental Brain Research, v.127, p.182-192, 1999.

WINSTEIN, C.J., POHL, P.S. Effects of unilateral brain damage on the control of goal-directed hand movements. Experimental Brain Research, v.105, p.16374, 1995.

WANG, J., \& SAINBURG, R.L. Mechanisms underlying interlimb transfer of visuomotor rotations. Experimental Brain Research, v.149, n.4, p.520-26, 2003.

WANG, J., \& SAINBURG, R.L. Limitations in interlimb transfer of visuomotor rotations. Experimental Brain Research, v.155, n.1, 1-8, 2004. 
WANG, J., SAINBURG, R.L. The dominant and nondominant arms are specialized for stabilizing different features of task performance. Experimental Brain Research, v. 178, p.565-570, 2007.

STERGIOU, N. Considerations of movement variability in biomechanics research. Innovative analyses of human movement, cap.2, p.54-56, 2004. 
Apêncice 1- Inventário de Dominância Lateral de Edimburgo (Oldfield, 1971).

Nome: $n^{\circ}:$

Assinale:

$(+)=$ realiza maioria das vezes

$(++)=$ sempre realiza

Faz-se uma marca em cada coluna, caso a probabilidade de uso da mão direita e esquerda seja a mesma.

\begin{tabular}{|l|l|l|l|}
\hline & & Esquerda & Direita \\
\hline 1 & Escrever & & \\
\hline 2 & Desenhar & & \\
\hline 3 & Arremessar & & \\
\hline 4 & Uso de tesouras & & \\
\hline 5 & Escovar os dentes & & \\
\hline 6 & Uso de Faca (sem garfo) & & \\
\hline 7 & Uso de colher & & \\
\hline 8 & Uso de vassoura (mão superior) & & \\
\hline 9 & $\begin{array}{l}\text { Ascender um fósforo (mão do } \\
\text { fósforo) }\end{array}$ & & \\
\hline 10 & Abrir uma caixa (mão da tampa) & & \\
\hline & \multicolumn{2}{|l}{} & \\
\hline & \multicolumn{2}{|l}{} & \\
\hline
\end{tabular}

